\title{
Atypical fetal development: Fetal alcohol syndrome, nutritional deprivation, teratogens, and risk for neurodevelopmental disorders and psychopathology
}

\author{
MICHAEL K. GEORGIEFF, ${ }^{a, b}$ PHU V. TRAN,${ }^{a}$ AND ERIK S. CARLSON ${ }^{c}$ \\ ${ }^{a}$ University of Minnesota School of Medicine; ${ }^{b}$ University of Minnesota College of Education and Human Development; and \\ ${ }^{c}$ University of Washington School of Medicine
}

\begin{abstract}
Accumulating evidence indicates that the fetal environment plays an important role in brain development and sets the brain on a trajectory across the life span. An abnormal fetal environment results when factors that should be present during a critical period of development are absent or when factors that should not be in the developing brain are present. While these factors may acutely disrupt brain function, the real cost to society resides in the long-term effects, which include important mental health issues. We review the effects of three factors, fetal alcohol exposure, teratogen exposure, and nutrient deficiencies, on the developing brain and the consequent risk for developmental psychopathology. Each is reviewed with respect to the evidence found in epidemiological and clinical studies in humans as well as preclinical molecular and cellular studies that explicate mechanisms of action.
\end{abstract}

Typical brain development follows an expectant rate during fetal and early neonatal life. The process of typical brain development has been well described at the neural circuit and gene expression levels (Allen-Institute, 2010; Thompson \& Nelson, 2001). Development is largely driven by genes that are independent of environmental stimuli, allowing the brain to develop relatively normally in spite of a wide range of environmental conditions, a concept particularly relevant to the diathesis-stress model of psychopathologic etiology (Monroe \& Simons, 1991). It is likely that this "clocklike" development assures a fundamentally similar outcome across a wide range of human experiences. Nevertheless, it is clear that experience plays a role in brain development and that the impact of experience is greater during periods of rapid growth and differentiation (Cross-Disorder Group of the Psychiatric Genomics Consortium, 2013). The remarkable overlap among genes identified as risk factors for multiple disparate psychopathologies suggests that a common fundamental grounding leads through environmental factors to multifinality of the behavioral phenotype in adulthood (Cross-Disorder Group of the Psychiatric Genomics Consortium, 2013).

The impact varies based on timing of the experience because the brain is not a homogenous organ. Rather, it is composed of different regions, cell types, and processes (e.g., myelination and neurotransmission). Each has a different de-

Supported in part by National Institutes of Health Grants HD029421 and AA024123 (to M.K.G.), NS099178 (to P.V.T.), and K08-MH104281 (to E.S.C.).

Address correspondence and reprint requests to: Michael K. Georgieff, University of Minnesota Masonic Children's Hospital, Division of Neonatology, 2450 Riverside Avenue, 6th floor East Building, Room 630, Minneapolis, MN 55454; E-mail: georg001@umn.edu. velopmental trajectory and therefore peak period of rapid growth and differentiation. For example, the hippocampus's peak period of development starts in the third trimester and proceeds through the first 18 months. Its peak is well before that of the prefrontal cortex, which matures later postnatally.

This differential development timing becomes crucial when determining the effect of a fetal environmental event on a circuit that relies on the integrity of both structures (e.g., the ventral tegmental area [VTA] loop). This neural circuit integrates multiple behaviors and dysfunction of it through imbalance of its tonic hippocampal input and phasic frontal lobe input has been implicated in the etiology of schizophrenia and drug addiction (Esmaeili \& Grace, 2013). To illustrate the differential effect of timing of a fetal environmental event, we can consider what occurs to its construction and function in a preclinical rodent model when a nutritional substrate that is crucial for neuronal growth and differentiation (i.e., iron) is deprived in the fetal and newborn period when hippocampal, but not frontal lobe, development is particularly rapid. In this illustrative case, early life iron deficiency results in an adult animal with significant hippocampal, but minimal frontal lobe, impairment. The effect at the circuit level is complex and results in hippocampal disinhibition, which allows for greater dominance of frontal lobe inputs into the VTA loop (Schmidt, Alvarez, Grove, Rao, \& Georgieff, 2012). Consequently, the adult shows greater cognitive flexibility on set-shifting tasks than always iron sufficient controls in spite of also demonstrating rather poor declarative memory. This example emphasizes the importance of both timing and duration of early life environmental events on subsequent adult functioning. 
Fetal environmental effects can cause acute functional changes to the brain that return to normal once the environmental effector is removed. In the case of short-duration environmental effects, the long-term effects may be minimal if no critical periods of development were missed and if environmental homeostasis can be reestablished. However, all of the early life environmental effects that are discussed in this article have been shown in clinical studies and preclinical models to cause disruption of adult function, suggesting important long-term changes to brain anatomy and the molecular biology of synaptic plasticity gene regulation.

From a societal standpoint, the cost to society of early life adverse environmental events stems from the long-term effects, manifested as loss of education and job potential, medical costs for treatment of mental health issues, and loss of opportunity to improve socioeconomic status. Policies and practices that do not ensure optimal early life environmental health represent a failure of a society to invest in its next generation. The adage "how are the children doing?" takes on full transgenerational biological meaning via mechanisms underlying the developmental origins of adult (mental) health and disease $(\mathrm{DOHaD})$ paradigm. In this article, we review three major categories of early life environmental disruptions that confer long-term risk to the mental health of humans: fetal alcohol exposure, teratogen exposure, and nutritional deprivation.

It should be noted that differentiating fetal from early postnatal life effects is relatively arbitrary on the following counts. First, it may be difficult to separate exposures into such defined epochs. Nutritional deficits accrued by the fetus carry forward into postnatal life. For example, iron is accreted primarily during the last trimester and is utilized by the fetus to support regional neural differentiation, myelination, and monoamine neurotransmitter production (Lozoff \& Georgieff, 2006). Fetal iron deficiency results in acute recognition memory failure, slower speed of neural processing, and a disengaged newborn infant (Amin et al., 2010; Siddappa et al., 2004; Wachs, Pollitt, Cueto, Jacoby, \& Creed-Kanashiro, 2005), symptoms that are completely consistent with the known biology (Lozoff \& Georgieff, 2006). However, low iron stores at birth due to reduced fetal accretion also results in reduced substrate for rapid postnatal brain growth and differentiation. The relatively slow transfer of postnatal dietary iron across the blood-brain barrier results in an extended period of additional postnatal brain iron deficiency and thus confers a risk to more, postnatally developing circuits. Similarly, teratogens can accumulate in the body during fetal life and thus affect fetal brain development acutely. Postnatally, those stored teratogens can continue to damage developing structures and alter gene expression. In contrast, fetal alcohol exposure clearly ends with delivery of the baby from the alcohol-consuming mother, thus removing any risk of postnatal exposure.

Second, the DOHaD hypothesis, initially known as the Barker hypothesis, initially focused on adult cardiovascular risk as a function of restricted fetal nutrition and growth (Bar- ker, 1997). Barker's conclusion that "fetal programming" accounted for the increased risk of hypertension, type 2 diabetes, and cardiovascular in the elderly instigated the search for fetal factors that mediate the effect. Findings since the original reports indicate that the effect is not solely restricted to fetal life, but that the transition from fetal to neonatal life happened to provide a convenient "cut point" to study, that is, a time when a human goes from one nutritional environment (i.e., intrauterine) to a potentially radically different one (i.e., extrauterine). A major refinement of Barker's "fetal programming" hypothesis came in the early 2000s when Gluckman and Hanson (2004) demonstrated that the predictive value of fetal growth restriction for adult heart disease was much greater if one considered the growth rate of the individual postnatally during the first months of life. Rapid postnatal weight gain after intrauterine growth restriction (IUGR) exacerbated the risk in adulthood (Gluckman \& Hanson, 2004), and it was postulated that any jarring change in environment early in life induces stress responses as indexed by altered hypothalamic-pituitary-adrenal axis regulation and pro-inflammatory responses as indexed by elevated pro-inflammatory cytokines. Both responses are injurious to developing organs such as the heart and blood vessel systems. If IUGR fetuses grew slowly postnatally, their risk of cardiovascular diseases was mitigated. The findings raised the possibility that a developmental window exists when metabolic set points are set for the life span, likely through epigenetic mechanisms.

Subsequent studies in premature infants, who frequently undergo severe growth restriction postnatally, also demonstrate an increased risk of central adiposity, early life hypertension, and insulin resistance. These infants would have had their growth restriction followed by rapid catch-up growth in the same developmental window as Barker's IUGR subjects (i.e., 24-40 weeks postconceptional age), but all of the events would have occurred in the extrauterine environment. The postnatal duration of the sensitive period for setting metabolic set points is unknown. Data from internationally adopted children demonstrating increased central adiposity and relative stunting suggest that the period may extend through the first year of life. Although the birth history of most of these children is poorly documented, it is clear that they undergo a period of malnutrition, stress, and growth restriction until placement (Johnson et al., 1992, 2010). Multiple endocrine mediators of growth and development are disrupted (Miller et al., 2010). Adoption into a resource-rich home typically stimulates rapid catch-up growth, consistent with the abrupt change in environmental conditions described by Gluckman and Hanson (2004), and accompanied by altered hypothalamic-pituitary-adrenal axis regulation (Gunnar \& Quevedo, 2008; Kertes, Gunnar, Madsen, \& Long, 2008).

Besides the peripheral effects such as stimulation of central adiposity, the concern is that both cortisol and pro-inflammatory cytokines cross the blood-brain barrier and can affect early brain development. Thus, Insel and others have proposed that the $\mathrm{DOHaD}$ principle applies to mental as well as physical health (Bale et al., 2010). Thus, while "fetal pro- 
gramming" remains an attractive and relatively easily studied construct, the definition of early life environmental effects on long-term neurodevelopment must be broadened to account for carryover effects from fetal life and the possibility that postnatal environmental events particularly during the first year affect life span neurodevelopment through similar mechanisms ascribed to "fetal programming." Randomized clinical trials support this construct. Iron supplementation of pregnant women from early pregnancy to 12 weeks postpartum significantly increases performance on working memory and inhibitory control in their offspring at 7-9 years of age compared to children whose mothers were not supplemented (Christian et al., 2010). In contrast, iron supplementation of 12- to 36-month-old children, whose mothers did not receive prenatal iron supplementation, had no effect on neurodevelopment at 7-9 years (Christian et al., 2011; Pongcharoen et al., 2011). Similarly, linear growth in the first 12 months postnatally strongly correlates with IQ at 9 years of age, but growth after 12 months had no impact (Pongcharoen et al., 2012). Clearly, the fetal period through 12 months postnatal age is of particular importance in maintaining fetal and early postnatal nutritional homeostasis in order to optimize long-term development (Pollitt, Gorman, Engle, Martorell, \& Rivera, 1993).

The duration of a term pregnancy in the human is 9 months and is typically divided into trimesters. Neurodevelopment can be affected by events in any of the fetal trimesters. Typically, events that occur in the first trimester have a larger impact on outcome than events in the third trimester because the neurologic processes that are disrupted are more fundamental in nature. These processes include structural embryogenesis in the first 8 weeks of pregnancy (when many mothers do not definitively know that they are pregnant), neurogenesis, and cell migration. The respective clinical syndromes of neural tube defect (e.g., spina bifida, anencephaly, and holoprosencephaly), microcephaly, and migration defects (e.g., lissencephaly) cause severe neurodevelopmental impairments. Events that occur in the third trimester typically cause less major disruptions but nevertheless can have significant impact on neural circuit construction. The latter is particularly important when relating fetal events to later risk of developmental psychopathology. All of the adverse fetal brain exposures discussed in this article follow these general rules of early versus late timing. For example, fetal alcohol exposure in the first trimester results in severe microcephaly and structural abnormalities, while the same exposure in the third trimester often spares head growth but results in more subtle deficits that may not become obvious for years (Bale et al., 2010).

A series of fundamental questions are thus raised when assessing environmental events in fetal life, brain development, and subsequent risk of psychopathology. Does altered early brain development due to fetal environmental events result in altered child and adult brain function, as indexed by altered behavior? If so, how predictable is the linkage? What accounts for the variability in behavioral outcomes following fetal environmental events? What are the mechanisms by which early life events permanently alter neural circuitry such that the behavioral phenotype remains abnormal despite correction of the abnormal fetal environment? Do disparate events that occur during a specific epoch in pregnancy result in a similar behavioral phenotype (i.e., unifinality) or does the nature of the fetal event matter in terms of structures that are affected?

To answer these questions, it is useful to consider the types of fetal environmental events that affect early brain development. Prenatal and early postnatal events affect early brain development by two basic pathways: events of omission and events of commission. Events of omission occur when factors important for normal brain development are absent. For example, premature delivery shortchanges the fetus of expectant intrauterine nutrients that are critical for brain development and are transported from mother to fetus during the third trimester. Not only does the prematurely born fetus fail to accrete those nutrients, but most preterm infants fail to thrive for months postnatally (Ehrenkranz, 2000) because they are difficult to nourish and because their metabolic needs are quite different than the in utero fetus.

Events of commission are defined as adverse events that happen to the brain because substances that should not be in the young brain are present. Classic examples of events of commission include fetal alcohol or teratogen exposure because these disruptors alter the architecture and metabolism of the developing brain. Clinically, the outcomes of many populations are a function of a combination of omitted and committed events. Events of commission can lead to events of omission. For example, fetal alcohol exposure, a clear event of commission, also reduces iron accretion by the fetal brain, leading to brain iron deficiency, a clear event of omission. Events of omission can also lead to secondary omission events. IUGR due to maternal malnutrition or maternal hypertension shortchanges the developing fetal brain of multiple nutrients that are critical for growth and development, including glucose, fatty acids, amino acids, iron, zinc, copper, folate, choline, and vitamin B12 (Rao \& Georgieff, 2002). However, infants with IUGR are also more vulnerable to neonatal encephalopathy at birth because of the fragile nature of their physiology. Neonatal encephalopathy is characterized by a reduced oxygen delivery to the brain, which is clearly an event of omission. The compounding of adverse events is frequently a greater risk to the brain than the individual components added together.

Behavior is the efferent expression of the brain (Hebb, 1949). Since Hebb's time, it has become apparent that while neuronal activity is the main driver of behavior, the glia play an important part in behavior as well. In addition, while neuronal anatomic complexity is closely correlated to functionality in certain brain structures (e.g., hippocampus), nonanatomic functions such as neuronal metabolism and neurotransmitter function are drivers of the brain's electrical potential. Environmental factors (e.g., fetal nutrition) can affect all cellular aspects of brain function from anatomy to electrophysiology. For example, fetal nutrients such as protein, fats, iron, zinc, and choline affect aspects of neuronal anatomy including 
cell number (cell division), size, and complexity. These same nutrients affect anatomical characteristics of oligodendrocytes that generate myelin and improve speed of processing, astrocytes that deliver nutrients and carry out reparative processes and microglia that are involved in cell trafficking and inflammatory responses. Astrocytes also provide both the "gliogenic" and "neurogenic niches," which are likely important for stress responses in hippocampal neurogenesis, and cortical thickness (Horner \& Palmer, 2003). The anatomic brain, however, is inert unless activated through its neurochemistry (e.g., neurotransmitters and ion channels) and its ability to generate action potentials (e.g., neurometabolism). The same nutrients responsible for anatomic integrity in the fetus also directly regulate neurotransmitter and neurotransmitter receptor expression as well as reuptake mechanisms. The fetal brain is the most metabolically active organ during development, consuming $60 \%$ of the body's total energy expenditure (Kuzawa, 1998). Much of that fetal energy metabolism is devoted to structural development including neurite extension and synaptogenesis during construction of neural circuits that underlie simple and complex behaviors and the energy required to support electrical activity of those circuits. Glucose, protein, iron, zinc, and choline have profound effects on mitochondrial and glycolytic metabolism that provide ATP to fuel that fetal growth and brain activity.

As noted earlier, the cost to society of early life environmental disruptors is through their long-term effects. Two major theories that are not mutually exclusive can account for long-term loss of synaptic efficacy. The first revolves around the concept of critical and sensitive periods and the effects of environmental events that occur during a critical or sensitive period. In this conceptual framework, adverse events that occur throughout a critical period of development result in permanent structural damage to the nervous system (Hensch, 2004). The impact of an adverse early life event on the adult behavioral phenotype will vary since each brain region and process is on a unique developmental trajectory. The permanence of the negative effect appears to depend on the adverse event lasting throughout the critical period. For example, neuronal iron deficiency disrupts hippocampal structure if it occurs during the period of rapid growth and differentiation (Postnatal Days 10 to 28 in the mouse). Repletion of iron within the critical period (i.e., Day 21) restores structural integrity and preserves adult memory function. In contrast, repletion outside of the critical window (i.e., Day 42) results in permanent structural and behavioral abnormalities (Callahan, Thibert, Wobken, \& Georgieff, 2013; Carlson et al., 2009; Fretham et al., 2012). In this conceptualization, the neurobehavioral deficits relate directly to the disordered neuronal structure and include poorer memory and stimulus gating (Fretham et al., 2012; Jorgenson, Sun, O'Connor, \& Georgieff, 2005; Pisansky et al., 2013). The former is consistent with studies of early iron deficiency causing poorer neurocognitive function and an increased risk of schizophrenia in adulthood in humans (Insel, Schaefer, McKeague, Susser, \& Brown, 2008; Lukowski et al., 2010).
The second conceptual framework revolves around the ability of early life events, particularly stress and specific nutritional deficiencies, to alter regulation of synaptic plasticity genes through epigenetic modifications (see below). Epigenetic modifications can involve methylation or hydroxylmethylation of DNA and methylation, acetylation, and other biochemical changes of histones. The sum positive or negative effect of epigenetic modification typically cannot be judged by the degree of modification, but instead through understanding whether the genes that are modified are repressed or activated and whether the function of the genes are positive or negative.

Epigenetic modification is the most investigated biological mechanism underlying fetal programming to date. Fetal programming refers to the mechanisms by which early life environmental stimuli alter how genes are expressed throughout the lifetime. Epigenetics is the study of how supragenomic changes established early in life can permanently alter gene expression and resultant phenotype, independent of alterations to the genome itself. Mechanisms of epigenetic modification include DNA methylation, histone modification, and modulation by small noncoding RNAs, all of which are capable of altering patterns of gene expression. DNA methylation is particularly well characterized and includes two waves in which the genome is demethylated and then remethylated de novo, allowing for a complete "reprogramming" of the methylome. The second wave of remethylation establishes the methylation pattern that persists into mature somatic tissues and takes place during early embryogenesis. At this stage, DNA methylation is particularly vulnerable to intrauterine environmental exposures such as stress, toxicants, and malnutrition. Altered methylation of genes or their regulatory domains during this period can lead to lasting changes in gene expression and respective adult phenotypes (Bale et al., 2010; Heijmans, Tobi, Lumey, \& Slagboom, 2009; Simmons, 2005; Tobi et al., 2009).

Maternal/fetal stress clearly alters DNA methylation of brain-derived neurotrophic factor (BDNF), an important growth and differentiation growth factor for the brain (Lubin, Roth, \& Sweatt, 2008). Growth factors are important for brain growth because they promote the effect of nutrients through signaling systems such as the mammalian target of rapamycin pathway. Neuronal mammalian target of rapamycin pathway activity is regulated by the presence of nutrients that are particularly important for growth and differentiation such as energy, protein, iron, oxygen, and zinc. Growth factors regulate the utilization of these essential nutrients to regulate actin polymerization as well as DNA transcription and protein translation rates, all of which in turn determine cell size and complexity (Fretham, Carlson, \& Georgieff, 2011; Wullschleger, Loewith, \& Hall, 2006). Reduction of BDNF levels in the hippocampus results in reduced downstream expression of genes that are critical for neuronal function. Lower BDNF levels during development are associated with abnormal neuronal structure in adulthood in preclinical models (Brunette, Tran, Wobken, Carlson, \& Georgieff, 2010; Fretham et al., 2012; Jorgenson et al., 2005). 
Several fetal/neonatal nutritional conditions alter brain epigenetic status in preclinical models. IUGR, a model of generalized fetal malnutrition, disrupts hippocampal histone methylation (Ke et al., 2014). It also alters BDNF DNA methylation (Ke et al., 2010), potentially through inducing activation of the stress axis hormones. Long-chain polyunsaturated fatty acids (e.g., docosahexaenoic acid) found in fish oils also epigenetically modify BDNF through DNA methylation. Early life iron deficiency has little effect on BDNF methylation, but instead exerts its effects on the genome through a direct effect on a family of iron-containing histone demethylases (JAR$\mathrm{IDs} / \mathrm{KDMs}$ ) that regulate BDNF expression (Blegen et al., 2013; Tran, Kennedy, Lien, Simmons, \& Georgieff, 2015). Finally, certain nutrients in the one-carbon family (e.g., choline, folate, and betaine) can act as methyl donors and affect both DNA and histone methylation status (Barua et al., 2014; Cho et al., 2013; Zeisel, 2017).

In summary, fetal environmental events can permanently alter the expression of genes that are critical to adult neural function. The effects can be circuit and region specific, thereby potentially altering the activity of circuits and leading to aberrant behavioral phenotypes in adulthood. The critical period and epigenetic conceptual frameworks are not mutually exclusive as altered structure will result in altered gene expression and vice versa.

For each of the fetal clinical conditions considered in the following sections, we explore the evidence at the epidemiologic, clinical, preclinical, and molecular levels that supports a causative association between the fetal condition and later development of psychopathology. The range of conditions represents both events of commission (fetal alcohol syndrome and teratogen exposure) and events of commission (single or multiple nutrient deficits). While it is tempting to ascribe a direct cause and effect pathway for any of these conditions, it is likely that any of the psychopathologies that are proposed to have developmental origins (including schizophrenia, autism spectrum disorder, depression/anxiety, and attention-deficit/ hyperactivity disorder) are polygenic, and potentially polyenvironmental in their etiologies (Bale et al., 2010; Basavarajappa \& Subbanna, 2016). Careful dissection of the relative contribution of each early life factor may identify potential treatment and prevention targets in order to reduce the overall risk of disease appearance later in life.

\section{Fetal Alcohol Spectrum Disorder (FASD) and Its Relationship to Developmental Psychopathology}

\section{Epidemiological and clinical studies}

Prenatal alcohol exposure is considered the most common cause of mental retardation (National Institute on Alcohol Aabuse and Alcoholism, 1990). High rates of psychopathology are seen in children with FASD, including externalizing and internalizing behaviors, sleep disorders, abnormal habits and stereotypies, and behavioral management problems, even in the absence of intellectual disability (Steinhausen, Willms,
\& Spohr, 1993; Streissguth et al., 1991). The high rates of psychopathology persist in adulthood and include substance disorders, mood disorders, psychotic disorders, personality disorders, anxiety disorders, and eating disorders (Famy, Streissguth, \& Unis, 1998). Fetal alcohol damage is associated with later onset of schizophrenia (Slavney \& Grau, 1978). Attention-deficit/hyperactivity disorder (ADHD) was found to be the most common comorbid disorder among children with FASD (52.9\%), followed by oppositional defiant disorder (12.9\%), conduct disorder (7.0\%), and autism spectrum disorder (ASD; 2.6\%; Lange, Rehm, Anagnostou, \& Popova, 2017). While FASD is associated with global executive impairments, executive function weaknesses are most commonly found and consist of impairments of planning, fluency, and set shifting (Kingdon, Cardoso, \& McGrath, 2016).

FASD results in changes to multiple neural circuits that can be imaged noninvasively in humans. High incidences of midline brain abnormalities of the corpus callosum such as hypoplasia or agenesis are seen after prenatal alcohol exposure (Bookstein et al., 2005, 2007; Bookstein, Sampson, Streissguth, \& Connor, 2001; Riley et al., 1995; Sowell, Mattson, et al., 2001; Sowell, Thompson, et al., 2001; Swayze et al., 1997). More recent studies examining white matter microstructure with diffusion tensor imaging have found global white matter changes that could account for dysfunction of multiple behavioral domains including working memory, mathematical ability, executive function, processing speed, intelligence, and interhemispheric transfer (Donald, Eastman, et al., 2015; Donald, Roos, et al., 2015; Fan et al., 2016; Fryer et al., 2009; Lebel, Rasmussen, Wyper, Andrew, \& Beaulieu, 2010; Lebel et al., 2008; Malisza et al., 2012; Spottiswoode et al., 2011; Taylor et al., 2015; Wozniak et al., 2006, 2009). FASD is also associated with changes in functional connectivity in cortical networks (medial prefrontal and posterior cingulate), the default mode network, corticostriatal networks (affecting working memory), and whole-brain connectivity (associated with lower global cognitive functioning; Roussotte et al., 2012; Santhanam et al., 2011; Wozniak et al., 2011, 2017). Hippocampal volume and declarative memory deficits are prominent long-term features of FASD in humans (Autti-Ramo et al., 2002; Willoughby, Sheard, Nash, \& Rovet, 2008). The degree of hippocampal volume loss in humans is directly correlated with the amount of memory deficit (Autti-Ramo et al., 2002; Willoughby et al., 2008).

\section{Preclinical models and molecular mechanisms}

Preclinical models have investigated the effect of fetal alcohol exposure on the developing brain and the subsequent consequences to the adult brain. The behavioral findings in the preclinical model animals, including rats, mice, and nonhuman primates, corroborate the findings in humans. Analysis of the brains from the models has provided biological plausibility at the regional anatomic and circuit level to support the hypothesis that fetal alcohol exposure results in psychopathology at an older age in humans. Molecular analyses of the 
brains from the models provide insights into the mechanisms of the long-term findings. In general, the long-term effects of fetal alcohol exposure follow the temporal and regionalization rules seen with nutrient deficiencies (Kretchmer, Beard, \& Carlson, 1996; Maier, Miller, Blackwell, \& West, 1999). Alcohol exposure during different trimesters in the rat resulted in regional brain area differences of cell loss and also contrasted with alcohol exposure throughout the entire pregnancy (Maier et al., 1999).

Preclinical models demonstrate that alcohol exposure results in both global and regional specific effects. Global effects are particularly prominent with early to middle gestation onset of exposure. Two doses of alcohol on Day 9 of a 21-day gestation results in volume and significant misshaping of the cerebral cortex, hippocampus, striatum, and cerebellum (Parnell et al., 2013). The regional effects of fetal alcohol exposure in the rodent demonstrate that the hippocampus is particularly vulnerable (Berman \& Hannigan, 2000; Livy, Miller, Maier, \& West, 2003; Miller, 1995), supporting similar findings in humans (Autti-Ramo et al., 2002; Willoughby et al., 2008). All subregions of the hippocampus are affected in rodent models. The dentate gyrus and CA1 have reduced neuronal number (Klintsova et al., 2007; Miller, 1995). Exposure restricted to the third trimester reduces the volume of CA1 due to lower cell number and reduced pyramidal cell density (Livy et al., 2003). Prenatal alcohol exposure also damages area CA3 (Ba, Seri, Aka, Glin, \& Tako, 1999).

The loss of hippocampal anatomy is accompanied by loss of synaptic plasticity across the life span in rodent models (Hablitz, 1986; Krahl, Berman, \& Hannigan, 1999; Swartzwelder, Farr, Wilson, \& Savage, 1988; Tan, Berman, Abel, \& Zajac, 1990). In vitro electrophysiological studies in hippocampal brain slices isolated from adult animals following prenatal alcohol-exposed animals demonstrate changes in synaptic activity (Berman \& Hannigan, 2000). The loss of electrophysiologic potential may result from abnormalities in glutamatergic neurotransmission (Kimura, Reynolds, \& Brien, 2000; Reynolds \& Brien, 1995; Thomas, Fleming, \& Riley, 2001). Fetal alcohol exposure also results in brain iron deficiency (Helfrich, Saini, Kling, \& Smith, 2017; Huebner, Blohowiak, Kling, \& Smith, 2016; Rufer et al., 2012), which in turn compromises glutamatergic neurotransmission (Jorgenson et al., 2005; Pisansky et al., 2013; Rao, Tkac, Townsend, Gruetter, \& Georgieff, 2003).

The translation of alcohol-induced hippocampal deficits from preclinical models to human long-term behavioral abnormalities extends beyond declarative memory deficits because the hippocampus is also central in circuits that support more complex behaviors. For example, tonic hippocampal input is critical for regulation of the VTA loop. Disruption of this input through compromise of hippocampal function with resulting imbalance between hippocampal and prefrontal cortical inputs has been proposed as a mechanism in schizophrenia (Esmaeili \& Grace, 2013; White, Joseph, Francis, \& Liddle, 2010). Dysregulation of the VTA loop has also been implicated in drug addiction research, and as noted above, the rate of drug addiction is higher in adults with FASD (Macht, Kelly, \& Gass, 2017). The hippocampus is central to the circuitry involved in sensory gating, a key behavior that is disordered in schizophrenia (Pisansky et al., 2013). Finally, the integrity of the hippocampus in early life is important in providing scaffolding for frontal lobe development later in childhood. While the prefrontal cortex may be directly injured by fetal alcohol exposure, it may also receive poor connections from an injured limbic system (Wachs, Georgieff, Cusick, \& McEwen, 2014). Fetal insults that initially cause declarative learning and memory deficits in the newborn period can manifest as attentional issues at older ages (Deregnier, Nelson, Thomas, Wewerka, \& Georgieff, 2000; Jabes, Thomas, Langworthy, Georgieff, \& Nelson, 2015).

In humans, prenatal alcohol exposure modifies the somatic cell DNA methylation (Portales-Casamar et al., 2016), providing evidence for potential epigenetic mechanism underlying the long-term changes in gene expression. Certainly, more studies are needed to establish this relationship. In animal models, fetal alcohol exposure alters expression of neural genes critical for important cellular processes, including proliferation, fate specification, migration, and differentiation (Kleiber, Mantha, Stringer, \& Singh, 2013; Sanchez-Alvarez, Gayen, Vadigepalli, \& Anni, 2013). These findings provide a molecular and cellular basis to explicate the neurodevelopmental deficits associated with prenatal alcohol exposure. The relationship between prenatal alcohol exposure and epigenetic modifications is more evident in the animal models. In line with limited data from humans, prenatal alcohol modifies DNA methylation patterns in mouse embryos (Hicks, Middleton, \& Miller, 2010; Liu, Balaraman, Wang, Nephew, \& Zhou, 2009), expression of noncoding RNAs implicated in epigenetic modifications (Laufer et al., 2013), and neural expression of DNA methylation modifiers such as DNMTs and MeCP2 (Gangisetty, Bekdash, Maglakelidze, \& Sarkar, 2014; Kim et al., 2013; Liyanage, Zachariah, Davie, \& Rastegar, 2015; Perkins, Lehmann, Lawrence, \& Kelly, 2013). Emerging evidence has also implicated prenatal alcohol exposure in modifying histone acetylation and methylation as another epigenetic link to the long-term gene dysregulation (Chater-Diehl, Laufer, \& Singh, 2017).

\section{Preclinical Models of Teratogen Exposure (Bisphenol- A) and Their Relation to Developmental Psychopathology}

Teratogens represent a major "commission" risk to the developing fetal brain. Teratogens typically fall into the categories of drug exposures and environmental toxicants. Alcohol (discussed above) easily fits into the teratogen category as an abnormal drug exposure. In all cases, they represent environmental molecules that are not needed for normal brain development. It is beyond the scope of this article to catalog the suspected brain effects of all teratogens. The following discussion focuses on bisphenol-A (BPA) because of growing 
evidence that potential endocrine disruptors during pregnancy significantly affect brain development.

\section{Epidemiological and clinical studies}

Fetal-neonatal exposure to BPA, a chemical used in the production of commonly used plastics, is associated with dysfunction in metabolism and reproductive development (Dolinoy, Huang, \& Jirtle, 2007). BPA can traverse the placenta and is found in fetal serum and full-term amniotic fluid, with highest levels found between 15 and 18 weeks gestation (Ikezuki, Tsutsumi, Takai, Kamei, \& Taketani, 2002). In humans, while the long-term effects of early life BPA exposure on neurobehavioral development remain controversial (Casas et al., 2015), accumulating evidence suggests a positive association between BPA exposure and risk of ADHD in male (Philippat et al., 2017; Tewar et al., 2016), internalizing and externalizing behavior in male (Evans et al., 2014), and social communication deficit in female children (Lim et al., 2017; Miodovnik et al., 2011). Braun et al. (2009) found a relationship between prenatal BPA exposure and externalizing behavior in 2-year-old girls but not boys using the Behavioral Assessment System for Children. Gestational urinary BPA concentrations were associated with some neurobehavioral measures at 3 years of age in this cohort (prospective birth cohort, 244 mothers). In particular, gestational BPA exposure was associated with higher scores for measures of anxiety, hyperactivity, emotional control, and behavioral inhibition (internalizing and externalizing behaviors). Results were more pronounced for externalizing behaviors: girls exhibited increases in hyperactivity, and boys exhibited decreases in hyperactivity (Braun \& Hauser, 2011; Tewar et al., 2016). Conversely, another study found that among boys (but not girls), prenatal BPA exposure was significantly associated with emotionally reactive and aggressive behaviors and higher syndrome scores (internalizing and externalizing problems) between the ages of 3 and 5 (Perera et al., 2012). Another study found no correlation between maternal BPA and infant neurobehavioral abnormalities in 5-week-old infant neurobehaviors; however, the authors noted that BPA concentrations in the maternal samples may have been below the threshold of neurobehavioral effects (Yolton et al., 2011).

\section{Preclinical models and molecular mechanisms}

The findings in humans suggest a connection between BPA and brain circuits that mediate ADHD, schizophrenia, social communication deficits, and internalizing/externalizing disorders. The biology underlying the behavioral deficits observed in human studies derives from the bodies of work in animal models and implicates abnormal structure in the hippocampus, caudate nucleus, and prefrontal cortex as well as significant effects on at least two neurotransmitter systems. These cellular and structural changes likely underlie the behavioral effects of prenatal BPA exposure.
BPA, like nutrient deficiencies, follows the rules of timing and regionalization. Rat dams were exposed to BPA in the last trimester of pregnancy and then randomized to additional exposure or placebo postnatally. Open field and elevated plus maze tests of anxiety-like behaviors administered during the juvenile and adult periods demonstrated that prenatal exposure reduced exploratory behavior and increased anxiety particularly in females (Gioiosa, Parmigiani, Vom Saal, \& Palanza, 2013). The sexually dimorphic behavior may be due to inhibition of estrogen receptor-beta (Xu et al., 2010).

Fetal and neonatal BPA exposure in mice compromises recognition memory as evidenced by poorer performance on the novel object recognition test, a finding that suggests compromise of the developing hippocampus (Tian, Baek, Lee, \& Jang, 2010). Adverse effects are seen at both the neuroanatomical and the neurotransmitter receptor levels. Reduced recognition memory is accompanied by lower NMDA receptor, consistent with alterations to the glutamatergic neurotransmitter system that is dominant in that brain area. The NMDA receptor effect is dose dependent. Low-dose BPA exposure decreases NMDA concentration, whereas high doses more selectively suppress NR1 than NR2A or B. This is developmentally important because NR1 combines first with NR2A and then developmentally switches to NR2B when longterm potentiation matures. BPA-induced alteration of subunits expression would be expected to alter hippocampal electrophysiologic development and capacity (Jorgenson et al., 2005). The hippocampus of prenatally BPA exposed monkeys also contains fewer dopaminergic neurons (Elsworth et al., 2013), suggesting compromise of a second neurotransmitter system. While the hippocampus has relatively low amounts of dopamine, its presence is important for providing salience to fear memories. Dopamine blockade increases the rate of fear memory extinction, whereas dopamine agonists slow the extinction rate (Menezes et al., 2015; Ponnusamy, Nissim, $\&$ Barad, 2005). The finding of fewer dopaminergic neurons is consistent with the reduced anxiety and fear that BPA-exposed mice demonstrate on open field and elevated plus maze tests (Tian et al., 2010).

Prenatal BPA exposure disrupts at least three hormone systems that have a role in brain development. In addition to the effect on estrogen receptor beta (Xu et al., 2010), stress-axis hormones may also be involved as fetal/neonatal BPA exposure alters glucocorticoid receptors more in females than males accompanied by greater anxiety in female offspring in adulthood (Poimenova, Markaki, Rahiotis, \& Kitraki, 2010). Furthermore, fetal/neonatal exposure acts as a thyroid hormone receptor antagonist in rats, potentially resetting neuronal metabolic set points and mitochondrial activity (Zoeller, Bansal, \& Parris, 2005). Reduction of neuronal metabolic activity would result in simpler dendritic structure and consequent loss of function in the same manner as seen with nutrient deficiencies (Bastian, von Hohenberg, Mickelson, Lanier, \& Georgieff, 2016).

The brain regions and neurotransmitter systems that are altered permanently by fetal/neonatal BPA exposure reside in 
neural circuits that mediate important complex behaviors including the VTA loop and mesolimbic-prefrontal connections. The involvement of these circuits' anatomy and neurochemistry provides a plausible biological basis for the psychopathology reported in human juveniles and adults, including anxiety, internalizing/externalizing behaviors, and schizophrenia.

In mice, there are evidence that fetal-neonatal BPA exposure alters cortical development by accelerating neuronal differentiation and migration during the early embryonic stage, resulting in a mistiming of critical development that had lasting effects into adulthood. The alterations were accompanied by changes to promoter-associated $\mathrm{CpG}$ islands suggesting that the long-term effects were epigenetic in nature (Itoh, Yaoi, \& Fushiki, 2012) Whole-genome DNA methylation is altered in a dose-dependent manner by BPA administered in physiologically relevant concentrations during pregnancy to the agouti mouse (Anderson et al., 2012). Provision of a diet enhanced with methyl donors (e.g., folate) that are known to modify $\mathrm{CpG}$ island and histone methylation status counteracts the long-term epigenetic effects of fetal/neonatal PBA exposure (Dolinoy et al., 2007).

Similarly to the epigenetic findings with early life BPA exposure, three recent studies showed that developmental exposure to Atrazine, a commonly used agricultural herbicide, also induces changes in histone methylation and DNA methylation patterns in the rodent germ cells across multiple generations, thereby linking Atrazine exposure to stable and transmissible epigenetic modifications (Gely-Pernot et al., 2015; Hao et al., 2016; McBirney et al., 2017). The effects on brain development remain to be determined.

\section{Preclinical Models of Select Nutrient Deficiencies and Their Relation to Developmental Psychopathology}

There is a substantial body of literature on the effect of fetal nutrition on adult mental health. All nutrients are important for brain development during the last trimester, but certain nutrients have a greater acute and lasting impact on the brain and behavior. These include macronutrients such as glucose, protein, and fats (especially long-chain polyunsaturated fatty acids) and micronutrients such as iron, zinc, copper, iodine, folate, choline, and vitamin B12. These higher impact nutrients demonstrate critical or sensitive periods for neurodevelopment where early life deficiency results in long-term dysfunction (Table 1). Several, including long-chain polyunsaturated fatty acids, iron, folate, and choline, as well as generalized fetal malnutrition, confer these long-term risks through epigenetic mechanisms (Georgieff, Brunette, \& Tran, 2015; Grissom \& Reyes, 2013; Ke et al., 2014; Tran et al., 2015; Tyagi, Zhuang, Agrawal, Ying, \& Gomez-Pinilla, 2015; Zeisel, 2017). A comprehensive review of each nutrient is beyond the scope of this article, but the principles are evident from well-studied nutrients such as iron deficiency and generalized fetal malnutrition, also referred to as IUGR. Both have been associated with an increased incidence of later onset of significant developmental psychopathologies such as schizophrenia (Eide et al., 2013; Insel et al., 2008), autism (Schmidt, Tancredi, Krakowiak, Hansen, \& Ozonoff, 2014) and depression/anxiety (Lukowski et al., 2010) and thus merit in-depth analyses across all levels of investigation from epidemiology to molecular biology. They stand as valuable paradigms for the biological plausibility of early nutrition effects on adult mental health (Pollitt et al., 1993).

\section{Epidemiological and clinical studies of iron deficiency}

Iron deficiency (ID) is the most common nutrient deficiency in the world (Walker et al., 2007). Fetal ID that affects brain development occurs in the context of maternal diabetes mellitus during pregnancy, maternal hypertension during pregnancy, chronic severe ID, or maternal anemia due to ID (Beard, 2001; Lozoff et al., 2006; Siddappa, Rao, Long, Widness, \& Georgieff, 2007). Multiple studies have demonstrated the association between gestational diabetes in the mother and subsequent risk of developmental psychopathologies, particularly ASD and schizophrenia, in the offspring. Gestational diabetes mellitus is more common among mothers who have children with ASD and is associated with greater deficits in expressive language among children with ASD (Krakowiak et al., 2012). The risk for ASD is increased for children of women with diabetes (Leonard, de Klerk, Bourke, \& Bower, 2006). Preexisting type 2 diabetes mellitus and exposure to gestational diabetes diagnosed before (but not after) 26 weeks gestation is associated with an increased risk of ASD in offspring (Xiang et al., 2015). In a meta-analysis, diabetes during pregnancy was significantly associated with development of schizophrenia (Cannon, Jones, \& Murray, 2002). Uncontrolled maternal diabetes also resulted in poorer performance on measures of intelligence, verbal ability, acquired knowledge, spatial ability, and sequence abilities (Rizzo, Metzger, Dooley, \& Cho, 1997). Gestational diabetes reduced expressive language performance in infants of diabetic mothers at 18, 30, and 72/84 months (Dionne, Boivin, Seguin, Perusse, \& Tremblay, 2008). An increased risk for mild to moderate intellectual disability was found in children of mothers with diabetes (Leonard et al., 2006). The role of ID in linking maternal diabetes to poorer brain development was demonstrated in infants of diabetic mothers born with low cord ferritin concentrations indicating fetal ID. These infants have behavioral and electrophysiological measures of poorer recognition memory throughout the first 12 months of life in spite of resolution of their neonatal ID (DeBoer, Wewerka, Bauer, Georgieff, \& Nelson, 2005; Nelson, Wewerka, Borscheid, Deregnier, \& Georgieff, 2003; Nelson et al., 2000; Siddappa et al., 2004).

The role of early life ID and anemia (most commonly due to ID) in psychopathology has been assessed independent of maternal diabetes during pregnancy. For mothers with anemia, there is increased risk of severe intellectual disability in their offspring (Hablitz, 1986). Fetal/neonatal ID results in behavioral and electrophysiological measures of poor rec- 
ognition memory of mother's voice at 2 months of age (Geng et al., 2015). Early postnatal ID in Chilean infants is associated with attentional control deficits at age 10 years and heightened risk taking, excessive alcohol use, and risky sexual behavior in adolescence (East et al., 2017). Iron deficiency anemia (IDA) during early infancy is also associated with dull affect and social reticence at age 5, leading to functional isolation later in childhood (East et al., 2017). IDA results in long-lasting effects such as slower reaction time and poorer inhibitory control (with correlated EEG findings) on a Go/ No-Go task in children 8 to 9 years after diagnosis of ID and treatment with iron supplementation (Algarin et al., 2013). Infants with ID have adversely affected social-emotional behaviors such as increased shyness and latency to interact with an examiner, decreased positive affect and soothability (Lozoff et al., 2008), as well as poor object permanence and memory encoding and retrieval (Carter et al., 2010). The effects of ID are long lasting, with decreased performance on measures of executive functioning and recognition memory at 19 years of age (Lukowski et al., 2010). This same group has now been followed out to 25 years, with formerly ID subjects having less completion of secondary school and fewer long-term relationships, and more negative emotions and feelings of detachment (Lozoff et al., 2013). Case control studies have shown that infants with ID have lower scores on measures of mental and motor development, alterations in visual recognition memory, and improvement in these measures with iron supplementation (Friel et al., 2003; Lozoff et al., 2003; Moffatt, Longstaffe, Besant, \& Dureski, 1994; Riggins, Miller, Bauer, Georgieff, \& Nelson, 2009; Shafir, Angulo-Barroso, Calatroni, Jimenez, \& Lozoff, 2006; Sherriff, Emond, Bell, \& Golding, 2001). Children with ID in infancy have poorer performance on tests of some specific cognitive functions such as executive function requiring inhibition and planning at 5 and 10 years, and spatial memory and selective attention in 11- to 14-year-olds (Congdon et al., 2012; Lozoff, Jimenez, Hagen, Mollen, \& Wolf, 2000).

Recent neuroimaging studies are beginning to provide anatomic evidence of altered neonatal brain structure due to fetal ID. A diffusion tensor imaging study showed that low maternal prenatal iron status alters markers of normal development of axonal pathways (such as corpus callosum, internal capsule, and the longitudinal fasciculus) and frontal cortical gray matter (Monk et al., 2016). In a resting-state magnetic resonance imaging (MRI) study, former IDA subjects showed alterations in default mode and dorsal attention networks (Algarin et al., 2017).

\section{Preclinical models and molecular mechanisms of fetal/ neonatal ID}

In animal models, fetal/neonatal ID showed similar neurological and behavioral deficits to the human cohorts (Lozoff \& Georgieff, 2006). Fetal/neonatal ID during critical periods of cortical development increases the risk of autism, ADHD, and schizophrenia pathogenesis (Erikson, Jones, \&
Beard, 2000; Gambling, Kennedy, \& McArdle, 2011; Schubert, Martens, \& Kolk, 2015). Preclinical models provide evidence for acute and long-term abnormalities in neuronal structure, connectivity, metabolism, and plasticity that are accompanied by changes in gene expression (Tran et al., 2016).

The neurobiological importance of iron in optimal fetal/ neonatal brain development is well established (Lozoff \& Georgieff, 2006; Rao, Tkac, Schmidt, \& Georgieff, 2011). Iron is a critical nutrient for the enzymatic activity of proteins involved in myelination (Beard, Wiesinger, \& Connor, 2003; Connor \& Menzies, 1996), energy metabolism (Goodman, Warshaw, \& Dallman, 1970; Willis, Brooks, Henderson, \& Dallman, 1987), and monoamine neurotransmission (Goodman et al., 1970; Willis et al., 1987). The proteins include hydroxylases (e.g., tyrosine and tryptophan hydroxylase for dopamine and serotonin, respectively) and cytochromes that modulate electron transport in mitochondria.

The effects of fetal/neonatal ID follow the rules of timing, dose, and duration (Kretchmer et al., 1996). Timing appears to be particularly important in determining the long-term behavioral phenotype following early ID. The prevalence of ID varies with age in the fetal and pediatric population. Three time periods are characterized by the highest prevalences: late fetal life, toddlerhood, and adolescence, particularly in menstruating females. ID in each of these epochs causes acute neurocognitive and motor effects (Geng et al., 2015; MurrayKolb \& Beard, 2007; Siddappa et al., 2004). However, only the two early time periods are associated with long-term effects in spite of iron repletion, suggesting that critical periods for brain structures exist in those early time periods. Consideration of which brain structures are rapidly developing when ID is present has informed our understanding of later childhood and adult behavioral phenotypes. For example, the late fetal period is characterized by rapid hippocampal development, onset of myelination, and sculpting of the dopamine neurotransmitter system. Fetal/neonatal ID compromises each of these, and behavioral phenotypes in humans are characterized by poorer declarative memory (Geng et al., 2015; Siddappa et al., 2004), slower speed of processing (Amin et al., 2010; Roncagliolo, Garrido, Walter, Peirano, \& Lozoff, 1998), and alterations in mood and affect (Wachs et al., 2005). However, dopaminergic frontal lobe findings that are highly characteristic of ID in toddlerhood are not a prominent feature of fetal/neonatal ID most likely because of the relatively rudimentary nature of the prefrontal cortex.

Preclinical models confirm the regional brain vulnerability to fetal/neonatal ID. Two types of models are utilized to understand the neurobiology. The classic dietary maternal ID model in which the dam is started on an ID diet early in gestation with continuation until either Postnatal Day 10 (term human brain equivalent) or Postnatal Day 21 (weaning) has been the mainstay model (Felt et al., 2006; Rao et al., 2003). More recently, genetically modified mice have been utilized to understand the role of iron in hippocampal neuronal development without the confounding factor of anemia (Carlson et al., 2009; Fretham et al., 2012). 
The bulk of the preclinical evidence in the literature is based on the dietary rat model. Gestational and gestational/lactational ID in rats alters brainwide fatty acid composition of myelin acutely during the period of deficiency (Connor \& Menzies, 1996) and causes long-term suppression of myelin basic protein gene expression in adulthood after iron repletion (Clardy et al., 2006). It alters dopamine and serotonin neurotransmission acutely in the neonatal period particularly in the nucleus accumbens, striatum, substantia nigra, and ventral midbrain. Mesocorticolimbic and nigrostriatal pathways are particularly vulnerable (Beard, Erikson, \& Jones, 2003; Pinero, Jones, \& Beard, 2001; Youdim \& Green, 1978). In adulthood, the cerebellum, frontal cortex, striatum, hippocampus, and midbrain show variations in markers of dopamine and serotonin metabolism, accompanied by alterations in behaviors that rely on these structures including negative geotaxis, forelimb placement, and novel object recognition (Unger et al., 2012).

Fetal/neonatal dietary IDA in the rat or nonanemic neuronal-specific ID in the mouse alters adult hippocampal metabolism and neurotrophic factor gene expression (Carlson et al., 2009; Tran, Fretham, Carlson, \& Georgieff, 2009), dendrite morphology (Brunette et al., 2010; Carlson et al., 2009; Fretham et al., 2012; Jorgenson, Wobken, \& Georgieff, 2003), electrophysiology (Jorgenson et al., 2005; Pisansky et al., 2013), and learning and memory behavior (Carlson et al., 2009; Felt \& Lozoff, 1996; Fretham et al., 2012; Schmidt, Waldow, Grove, Salinas, \& Georgieff, 2007). Persistence of these effects into adulthood in the dietary rat model occurred in spite of initiation of iron treatment during the lactation phase (Unger et al., 2012). In the specifically neuronal ID model, adult structural and behavioral changes were prevented when iron was repleted in the neurons during lactation (Fretham et al., 2012). The likely cause of the discrepancy between the dietary rat and genomic mouse models is that the rat is anemic and total body iron deficient and thus the repletion period is much longer compared to the genomic mouse model. The long-term findings in both models suggest a critical period for iron during development, most likely during the rapid brain growth phase immediately postnatally.

The adult behavioral phenotypes seen in both rodent species models are instructive with respect to developmental psychopathology. An important finding from the nonanemic hippocampal neuronal ID mouse models was that extrahippocampal abnormalities were also noted in the striatum in spite of normal iron content (Carlson et al., 2010) in addition to the spatial learning and memory deficits that would be expected from a hippocampal iron deficit (Carlson et al., 2009; Fretham et al., 2012). Specifically, striatal metabolism is compromised by hippocampal ID along with procedural memory behaviors that depend on an intact striatum (Carlson et al., 2010). The findings emphasize the interconnectedness of these brain areas as they work together in integrated, complex neural circuits. The striatal findings may well be driven by compromised hippocampal-derived glutamatergic neurons (Jorgenson et al., 2005) failing to normally potentiate dopaminergic neurons in the VTA loop. Similar circuit effects were demonstrated by Pisansky et al. (2013) in the nonanemic hippocampal neuron specific and the dietary IDA models ( $\mathrm{Pi}$ sansky et al., 2013). Paired-pulse inhibition (PPI), a measure of sensory gating often utilized as a model of schizophrenia, is dependent on normal hippocampal function in the complex circuitry that underlies this behavior. PPI is highly abnormal in the adult mouse and rat following fetal/neonatal ID, suggesting that hippocampal damage sustained in the neonatal period continues to have ramifications at the circuit level. The finding also suggests a plausible biology for the epidemiologic finding that fetal ID increases the risk of schizophrenia in adulthood in humans (Insel et al., 2008).

Schmidt et al. $(2007,2012)$ also found evidence of circuitlevel dysfunction in adulthood following fetal/neonatal dietary ID in the rat. Formerly ID adult rats showed expected impairments in spatial memory (Schmidt et al., 2007), but superior performance on set-shifting paradigms (Schmidt et al., 2012). The spatial memory abnormalities are consistent with the anatomic and electrophysiologic studies in the model that showed permanent hippocampal damage (Brunette et al., 2010; Jorgenson et al., 2005). However, the increased cognitive flexibility seen in the set-shifting paradigm implies intact or enhanced frontal lobe function. The lower amount of hippocampal inhibition allowed the rats to utilize frontal strategies to successfully complete the set-shifting paradigm. This finding illustrates an important circuitry principle because the hippocampus and frontal cortex coordinately regulate VTA loop activity. Disruption of the balance of these inputs is thought to underlie the disordered decision making observed in schizophrenia (Belujon \& Grace, 2008; Lisman et al., 2008). Selective lesioning of either hippocampal or frontal inputs results in a schizophrenia phenotype in the rodent (Esmaeili \& Grace, 2013).

Nonhuman primates have been used in a small number of studies to demonstrate the importance of timing of ID in a more humanlike model. Prenatal ID results in an impulsive behavioral phenotype in the juvenile animal, while postnatal ID results a hesitant, wary phenotype (Golub, 2010). The findings are consistent with those in humans. Felt et al. (2006) have described a hesitant/wary behavioral phenotype in postnatally ID animals and have postulated that the effects are due to compromise of dopaminergic projections to the frontal lobe from the striatum. In contrast, the ADHD phenotype seen with prenatal ID may be due to a secondary compromise of hippocampal-derived projections to the prefrontal cortex

As noted previously, two potential principles can explicate these long-term negative effects. First, in terms of a structurefunction relationship, poorly formed structure can result in poor neural plasticity and gene regulation. Classical neurotransmitters such as dopamine, whose synthesis is dependent on iron-dependent tyrosine hydroxylase, can compromise neuron number in the developing cortex (Kolk et al., 2009; Popolo, McCarthy, \& Bhide, 2004). Second, emerging evidence suggests fetal/neonatal ID also alters the function of iron-dependent epigenetic modifiers, leading to stable 
changes in chromatin remodeling, providing an alternative mechanism underlying the long-term gene dysregulation in neurons (Tran et al., 2015).

In preclinical models, early life IDA permanently alters the regulation of genes that are important for adult function, including neurological networks underlying synaptic plasticity, major depression, anxiety, autism, and schizophrenia (Brunette et al., 2010; Carlson, Stead, Neal, Petryk, \& Georgieff, 2007; Patton, Coe, Lubach, \& Connor, 2012; Tran, Dakoji, Reise, Storey, \& Georgieff, 2013; Tran et al., 2016). Epigenetic modifications of these gene networks by iron are highly plausible mechanisms to explain these long-term findings because two of the known epigenetic mechanisms (i.e., methyl-cytosine hydroxylation and histone methylation) are iron dependent and are mediated by two families of iron-containing proteins: the ten-eleven-translocation methyl-cytosine hydroxylases (TETs) and the methyl-lysine demethylases (KDMs and JARIDs). Both protein families require iron for their catalytic activity (Kouzarides, 2007; Pedersen \& Helin, 2010; Ponnaluri, Maciejewski, \& Mukherji, 2013). KDMs interact with histone deacetylases (Barrett et al., 2007; Chang, Chen, Zhao, \& Bruick, 2007; Chicas et al., 2012; Ramadoss, Chen, \& Wang, 2012; Suh, Aoyama, Matsumori, Liu, \& Swanson, 2005), further supporting a mechanistic link between neuronal iron status and epigenetic modifications. The findings of fetal/neonatal ID effects on TET activity remain unknown. In contrast, the persistently dysregulated KDMs accompanied by substantial changes in histone methylation at the Bdnf locus (Blegen et al., 2013; Tran et al., 2015), suggesting KDM dysfunction in the adult hippocampus following early life ID, provides a strong rationale for KDM's role in reprogramming gene regulation. In addition to the intracellular iron content, KDMs may be further regulated by iron-dependent proline hydroxylases (PHDs), thereby potentiating the effect of early life ID. Iron availability is essential for PHD to hydroxylate proline residues of HIF1a (Kaelin \& Ratcliffe, 2008; Nandal et al., 2011), which in turn directly regulates the expression of KDMs (Beyer, Kristensen, Jensen, Johansen, \& Staller, 2008; Lee, Choi, Oh, Park, \& Park, 2014; Mudie et al., 2014; Niu et al., 2012; Pollard et al., 2008). PHD1 expression is upregulated acutely in ID hippocampus (Carlson et al., 2007) and is normalized following iron treatment in the formerly ID hippocampus (Tran et al., 2016). The finding that KDMs remain dysregulated while PHD effect is resolved in adulthood points to a role of PHD in reprogramming of KDMs during the neonatal period. Elucidating the iron-dependent epigenetic mechanisms and their roles in reprogramming neural genes remains an emerging field and an active area of research.

\section{Epidemiological and clinical studies of IUGR}

IUGR occurs in $10 \%$ of pregnancies. Worldwide, the most common etiology of IUGR is maternal undernutrition, while in the United States the most common cause is nutrient restriction due to placental insufficiency from maternal hyperten- sion. Maternal infections particularly early in the pregnancy also cause IUGR. Each would be expected to have differential effects on the developing brain, and animal models can provide such insight. All etiologies result in restriction of nutrient flow from mother to fetus and result in a fetus that is smaller than its genetic potential. Both maternal malnutrition and IUGR have been epidemiologically associated with increased risks of developmental psychopathologies, including schizophrenia, autism, depression, and neurocognitive delay.

The relationship of IUGR to schizophrenia has been documented in several studies (Susser et al., 1996; Susser \& Lin, 1992). A meta-analysis revealed that birth weight $<2000 \mathrm{~g}$ and $>2500 \mathrm{~g}$ is significantly associated with development of schizophrenia (Cannon et al., 2002). Not only is a birth weight of less than $2500 \mathrm{~g}$ at term significantly associated with increased risk of schizophrenia, but a significant linear trend of increasing odds ratios with decreasing birth weight has been observed for infants with birth weights greater than 2500g (Abel et al., 2010). Of note, the same risk pattern has been shown for other psychiatric categories, including any psychiatric diagnosis; alcohol and drug disorders; affective disorders; and neurotic, stress-related, and somatoform disorders (Abel et al., 2010).

The risk of autism is associated with daily smoking during pregnancy (a risk factor for IUGR), and with being low weight for gestational age (Hultman, Sparen, \& Cnattingius, 2002). Depression in adulthood has also been associated with having had IUGR as a fetus. Young adults, who were born very low birth weight and small for gestational age reported significantly higher use of antidepressants, higher scores on the Beck Depression Inventory, and more likely to report a depression diagnosis than control subjects and very low birth weight infants born appropriate for gestational age (AGA; Raikkonen et al., 2008). A prospective study of IUGR infants born preterm compared with age-match preterm AGA and term AGA controls found decreased verbal and full-scale IQ scores; IUGR and preterm AGA infants had lower performance IQ than term control subjects (Morsing, Asard, Ley, Stjernqvist, \& Marsal, 2011). Small body size at birth significantly correlates with increased symptoms of ADHD in children ages 5 to 6 years old (Lahti et al., 2006). Being small for gestational age and born preterm is significantly correlated with risk of psychiatric hospitalization for drug and alcohol dependency in adulthood (Nosarti et al., 2012). Placental pathology consistent with underperfusion, a hallmark of IUGR, is associated with poorer cognitive, language, and motor performance at 2 years of age in near-term small for gestational age infants (Parra-Saavedra et al., 2014).

Neuroimaging studies confirm the global and regional effects of IUGR on neuroanatomy seen in preclinical models. Globally, IUGR infants have reductions in absolute cortical gray matter volume and overall brain tissue volume, and lack of postnatal catch-up brain growth. The anatomic findings correlate with reductions in attention and interaction capacity at term, and less mature neurobehavioral development on the Assessment of Preterm Infant Behavior (Tolsa et al., 2004). 
Several studies have found changes in regional brain size of IUGR infants. IUGR infants have reductions in frontal lobe and cerebellar volumes (Caetano et al., 2015) as well as reduction in hippocampal volume on MRI (Lodygensky et al., 2008). Fetuses with late-onset IUGR had deeper measurements of left and right insula and cingulate fissure as well as smaller intracranial, total brain, left opercula, and right opercula volumes (Egana-Ugrinovic, Sanz-Cortes, Figueras, Bargallo, \& Gratacos, 2013). In another study, IUGR fetuses had reductions in brain volume, but no demonstrable delay in cortical maturation based on grading of sulci and gyri; instead, they showed evidence of accelerated cortical development on these measures (Businelli, de Wit, Visser, \& Pistorius, 2014). IUGR infants had texture changes in several brain regions including the frontal cortex, cingulum, basal ganglia, midbrain, and cerebellum, indicative of microstructural differences and possibly brain reorganization compared to AGA infants (Sanz-Cortes et al., 2013). IUGR altered markers of maturation in frontal white matter, thalami, centrum semiovale, and pons associated with cognitive disorders in $36 \%$ of children at follow-up (Arthurs et al., 2017). A tractography, a 3-D modeling of neural track using diffusion tensor imaging data, study showed that IUGR is associated with altered connectivity in motor and cortico-striatal-thalamic networks (Eixarch, Munoz-Moreno, Bargallo, Batalle, \& Gratacos, 2016). A stereological study of postmortem brain tissue of IUGR infants found severe reduction of total cell numbers in the cortex, but not in other developmental zones (Samuelsen et al., 2007). A brain network topology study showed evidence of brain reorganization in IUGR infants at 1 year of age (Batalle et al., 2012). IUGR infants had decreases in measures of global and local connectivity, which were associated with abnormal performance in later cognitive, language, and motor outcomes at 2 years of age (Batalle et al., 2012). Structural MRI showed that 12-month-old IUGR infants had gray matter reductions in temporal, parietal, frontal, and insular regions; increased white matter in temporal regions compared to the AGA group and in frontal, parietal, occipital, and insular regions compared to term group; and decreased white matter in the cerebellum compared to term infants (Padilla et al., 2011). Functional consequences at the electrophysiologic and behavioral levels occur as a function of degree of IUGR. IUGR results in markers of delayed maturation of EEG, and associated delay in neuromotor development (YerushalmyFeler et al., 2014). Poorer intellectual performance at 7 years of age is associated when poor weight gain occurs postnatally in infants with IUGR (Pylipow et al., 2009), indicating that sensitive periods for brain growth and connectivity to nutrient availability extend beyond the fetal period.

\section{Preclinical models and molecular mechanisms of IUGR}

IUGR is not a single nutrient disorder; rather, it represents the anthropometric end result of global fetal malnutrition. Placental transfer of nutrients is the final common pathway from the mother to the developing fetus, and disruption of that process by any number of conditions results in the "unifinality" of retarded or restricted intrauterine growth. The failure to grow reflects primarily macronutrient (i.e., protein and calorie) malnutrition although micronutrient deficits (e.g., iron ID) are also prevalent and can restrict somatic and brain growth (Chockalingam, Murphy, Ophoven, Weisdorf, \& Georgieff, 1987; Georgieff, Mills, Gordon, \& Wobken, 1995). The traditional assessment of growth restriction through anthropometric analysis of weight, length, and head circumference for estimated gestational age is a blunt tool that does not have the precision to detect differential effects of the various etiologies of growth restriction on the developing brain.

Multiple preclinical models of IUGR have been developed because of the intense interest in Barker's observation of "fetal programming" of adult cardiovascular disease (Barker, 1997; Gluckman \& Hanson, 2004). Typically, rodent models have predominated because their short life spans allow for assessment of adult outcomes following fetal nutrient restriction events. The two most commonly used models are maternal dietary restriction and uterine artery (UA) ligation. Maternal dietary restriction is usually accomplished through reducing total food consumption during the entire pregnancy, thus shortchanging the mother of macro- and micronutrients. This approach models severe malnutrition that often presents in the "majority world." Individual nutrients such as protein or energy (calories) are restricted in some experiments while we maintain the rest of the diet in order to isolate the specific role of the nutrient in question. UA ligation in late gestation accomplishes a similar fetal nutrient restriction as the dietary models but does so without compromising maternal health status. It models the IUGR that occurs as a consequence of gestational hypertension in an otherwise nutritionally sufficient mother, seen primarily in "Westernized" countries.

Preclinical models other than rodents (e.g., sheep) have been used to assess the effects of IUGR predominantly on fetal and neonatal metabolism in order to provide information about insulin resistance and cardiovascular risk (Hay, Brown, Rozance, Wesolowski, \& Limesand, 2016). However, sheep are limited in the information they can provide about brain development and risk of later psychopathology. Rodents are the preferred model for studying IUGR on brain development because of their robust behavioral repertoire and the analogies that can be drawn between their abnormalities and those of humans (Table 2).

All nutrients are needed for normal brain development. As IUGR preclinical models typically restrict global nutrient delivery from mother to fetus, global effects are observed in the brain. Differential regional effects, where one brain area may be more affected than another, are largely related to relative metabolic rates (and thus nutrient demands) of the affected regions with those regions with higher metabolic demands at the time of the nutrient restriction being most affected. Regional metabolic demands are driven by growth rates, which in turn are driven by the age of the fetus. In humans, malnutrition early in pregnancy (or throughout pregnancy) results in global loss of brain volume and microcephaly (Winick, 
Table 1. Importance of timing of nutrient deficiency on long-term brain developmental outcomes

\begin{tabular}{|c|c|c|c|c|c|c|}
\hline Factor & & Age & Risk for deficiency & Critical period & $\begin{array}{l}\text { Affected brain regions } \\
\text { and (neural processes) }\end{array}$ & $\begin{array}{l}\text { Long-term impact after } \\
\text { resolution of nutrient deficit }\end{array}$ \\
\hline \multirow[t]{5}{*}{ Nutrient } & Protein & Fetus & $\begin{array}{l}\text { Maternal malnutrition; } \\
\text { maternal } \\
\text { hypertension }\end{array}$ & Third trimester & \multirow{2}{*}{$\begin{array}{l}\text { Cortex, eye, hippocampus } \\
\text { (proliferation, } \\
\text { differentiation, } \\
\text { synaptogenesis, growth } \\
\text { factors expression, and } \\
\text { myelination) }\end{array}$} & $\begin{array}{l}\text { Lower IQ at } 7 \text { years of age } \\
\text { (Pylipow et al., 2009) }\end{array}$ \\
\hline & & Child & $\begin{array}{l}\text { Variable based on } \\
\text { growth rates }\end{array}$ & $\begin{array}{l}6 \text { months- } \\
10 \text { years }\end{array}$ & & $\begin{array}{l}\text { Impaired cognition (Pollitt, } \\
\text { Gorman, Engle, Martorell, } \\
\text { \& Rivera, 1993) }\end{array}$ \\
\hline & \multirow[t]{2}{*}{ Iron } & Fetus & $\begin{array}{l}\text { Maternal anemia; } \\
\text { maternal diabetes; } \\
\text { smoking during } \\
\text { pregnancy }\end{array}$ & Third trimester & \multirow{3}{*}{$\begin{array}{l}\text { White matter, striatal- } \\
\text { frontal connectivity, } \\
\text { hippocampal-frontal } \\
\text { connectivity } \\
\text { (myelination, dopamine } \\
\text { synthesis, } \\
\text { neurometabolism, } \\
\text { migration, and } \\
\text { differentiation) }\end{array}$} & $\begin{array}{l}\text { Lower recognition and } \\
\text { working memory (Riggins, } \\
\text { Miller, Bauer, Georgieff, \& } \\
\text { Nelson, 2009) }\end{array}$ \\
\hline & & $\begin{array}{l}\text { Infant and } \\
\text { toddler }\end{array}$ & $\begin{array}{l}\text { Rapid growth, poor } \\
\text { dietary sources, } \\
\text { intestinal blood } \\
\text { loss; intestinal } \\
\text { parasites }\end{array}$ & $\begin{array}{l}6 \text { months- } \\
24 \text { months }\end{array}$ & & $\begin{array}{l}\text { Increased hesitancy and } \\
\text { wariness; increased } \\
\text { depression; motor } \\
\text { abnormalities; slower } \\
\text { processing (Lukowski } \\
\text { et al., 2010; Shafir et al., } \\
\text { 2008) }\end{array}$ \\
\hline & Zinc & $\begin{array}{l}\text { Fetus and } \\
\text { toddler }\end{array}$ & Maternal deficiency & $\begin{array}{l}\text { Pregnancy- } \\
24 \text { months }\end{array}$ & & $\begin{array}{l}\text { Decreased novelty preference } \\
\text { as toddler (Adamo \& } \\
\text { Oteiza, 2010), decrease } \\
\text { working memory function } \\
\text { (Fuglestad, Kroupina, } \\
\text { Johnson, \& Georgieff, } \\
\text { 2016) }\end{array}$ \\
\hline Teratogens & Alcohol & Fetus & $\begin{array}{l}\text { Alcohol consumption } \\
\text { during pregnancy }\end{array}$ & $\begin{array}{l}\text { Pregnancy- } \\
12 \text { months }\end{array}$ & & \\
\hline
\end{tabular}


Table 2. Integrated approaches between preclinical models and humans that provide biological plausibility in assessment of nonfatal developmental disorders

\begin{tabular}{|c|c|c|}
\hline Brain assessment & Human & Preclinical model \\
\hline Behavior & Yes & Yes (fit to human) \\
\hline Neuroanatomy & $\begin{array}{l}\text { Neuroimaging } \\
\text { autopsy (rare) }\end{array}$ & Neuroimaging microscopy \\
\hline Electrophysiology & EEG, ERP & Invasive in vivo and ex vivo recording \\
\hline Metabolism & MRS & $\begin{array}{l}\text { MRS } \\
\text { Direct biochemical assay, including } \\
\text { metabolomics of tissue/CSF }\end{array}$ \\
\hline Regulation & $\begin{array}{l}\text { Autopsy (rare) } \\
\text { CSF analysis (unusual) }\end{array}$ & $\begin{array}{l}\text { Tissue/CSF gene expression and } \\
\text { proteomics }\end{array}$ \\
\hline
\end{tabular}

Note: ERP, event-related potential. MRS, magnetic resonance spectroscopy. CSF, cerebrospinal fluid.

1971). The microcephaly in humans is due to fewer cells and lower amounts of DNA and RNA (Rosso, Hormazabal, \& Winick, 1970; Winick, 1971; Winick, Rosso, \& Waterlow, 1970). First trimester viral infectious agents such as cytomegalovirus also restrict neurogenesis and result in microcephaly (Kagan \& Hamprecht, 2017; Swanson \& Schleiss, 2013). Migration defects are more prominent with earlier nutritional abnormalities.

In contrast, nutrient deficiencies that occur later in gestation have less global effects on neurogenesis, but more intense effects on neural differentiation in regions that are developing just prior to birth (e.g., hippocampus). Selective disruption of regional development can contribute to unbalanced neural circuit function later in life.

An extensive meta-analysis of the literature on adult neurodevelopmental outcomes following UA ligation in rats, mice, and guinea pigs was recently reviewed by Basilious, Yager, and Fehlings (2015). Global effects were noted in all of the models specifically related to the degree of somatic growth restriction. Ventricular enlargement, indicative of reduced brain volume, was common across species (Mallard, Rehn, Rees, Tolcos, \& Copolov, 1999; Rehn et al., 2004; Ruff et al., 2017). The loss of brain volume is due to compromise of both white and gray matter. Oligodendrocyte precursors are reduced throughout the brain, resulting in a delay in onset of myelination (Olivier, Baud, Evrard, Gressens, \& Verney, 2005; Reid et al., 2012) and an overall loss of myelination in adulthood (Ruff et al., 2017). Major white matter tracts are reduced in volume and density (Delcour, Olivier, et al., 2012; Delcour, Russier, et al., 2012; Ruff et al., 2017). The loss of white matter can be widespread, including within the corpus callosum, brainstem, hippocampus, and somatosensory cortex (Delcour, Olivier, et al., 2012). The profound effects on white matter are not surprising because IUGR compromises maternal-fetal oxygen transport and oligodendrocytes are highly sensitive to hypoxia.

Generalized gray matter volume loss in IUGR models occurs predominantly from global and regional loss of neurons through neuronal cell death and/or apoptosis (Delcour, Olivier, et al., 2012; Mallard, Loeliger, Copolov, \& Rees, 2000). Be- yond reduced neuronal numbers, dendrite branching patterns are less complex and contribute to the volume loss particularly in the hippocampus (Dieni \& Rees, 2003). Neuronal function is clearly related to dendrite branching complexity; thus, the loss of complexity due to the substrate restriction of IUGR would be expected to compromise behaviors that are dependent on the affected structures. Neuronal loss and loss of morphological integrity is found in all hippocampal areas (Mallard et al., 2000; Ruff et al., 2017), the caudate nucleus (Rehn et al., 2004; Ruff et al., 2017), the cerebral cortex (Mallard et al., 1999), the medial and entorhinal cortex (Basilious et al., 2015), and the cerebellum (Mallard et al., 2000).

Beyond the structural changes, IUGR due to UA ligation also compromises signaling pathways that are critical for establishment and maintenance of synaptic plasticity. BDNF expression is reduced throughout the brain (Nishigori, Mazzuca, Nygard, Han, \& Richardson, 2008) and specifically in the hippocampus (Dieni \& Rees, 2005). The hippocampus is highly dependent on glutamatergic signaling, which is disrupted significantly by IUGR. NMDA receptor subunit expression is reduced overall, and a delay in the maturational switch of subunit NR2a to NR2b occurs (Catteau et al., 2011; Schober et al., 2009). Neuroprotective pathways in the cortex and hippocampus are compromised as evidenced by an increase in the proapoptotic p53 protein and a reduction in the anti-apoptotic Bcl-2 protein (Ke et al., 2005; Lane et al., 2001).

Overall, preclinical models of late fetal IUGR due to placental insufficiency indicate widespread acute abnormalities, many of which carry forward into adulthood. The changes are found at the anatomic and signaling levels and are particularly prominent in regions that are rapidly developing and demonstrate critical periods of development in the late fetal/early neonatal stages. UA ligation results in adult behavioral abnormalities that rely on the regions that were affected in the neonatal period. Specifically, cerebellar, hippocampal, and cortical injury due to IUGR results in abnormalities of gait, memory, object recognition, and spatial processing in adulthood (Basilious et al., 2015).

In considering the epidemiologic data in humans linking IUGR to developmental psychopathologies that emerge later 
in life, it is important to note that all of the fetally affected regions are destined to be interconnected postnatally to establish functional circuits underlying far more complex behaviors. Thus, a multiplicative or ripple effect throughout the nervous system likely occurs through complex circuits (e.g., the VTA loop or mesolimbic frontal connections), thus providing the anatomic framework for abnormalities in attentional regulation, ordered thinking, cognitive flexibility, sensory gating, and set-shifting behaviors that have been noted in adult survivors of IUGR. For example, rats with UA ligationinduced IUGR have damage to hippocampal area CA1 and prefrontal cortex and demonstrate hyperactivity (Delcour, Olivier, et al., 2012; Delcour, Russier, et al., 2012) similar to the ADHD phenotype described in humans. Prepulse inhibition abnormalities have been noted in the guinea pig model of IUGR (Rehn et al., 2004). Impaired PPI has been utilized as a marker of the sensory gating abnormalities in schizophrenia (Rehn et al., 2004), the incidence of which is increased in adults following IUGR. The behavioral studies in the preclinical models provide biological plausibility for primary (e.g., learning and memory deficits) as well as downstream complex behavioral abnormalities (i.e., sensory gating) noted in humans following IUGR.

Similar to the effects of ID, the role of timing in driving the acute and long-term abnormalities should be appreciated with IUGR. Late onset IUGR, as seen with the late gestation UA ligation model, induces severe, but relatively short-lived reductions in critical nutritional/metabolic substrates. This "one-hit" model produces a large "area under the curve" effect more from the large dose of the insult, as opposed to its duration (Kretchmer et al., 1996). An encephalopathic insult relegated to a brief epoch significantly damages only those regions with the greatest nutrient demand. Regions that have a more protracted critical period of development (and that show large amounts of plasticity) theoretically have an opportunity to recover, while those with relatively brief critical periods (and lesser plasticity) likely end up with permanent effects. Studying the effect of early versus late onset fetal UA ligation is technically challenging in the rodent due to excessive fetal demise in the early treatment group. However, the question has been studied in fetal sheep and supports the principle that timing matters. Second-trimester UA ligation in sheep results in more widespread white matter injury and neuroinflammation in the cortex when compared to third-trimester UA ligation (Alves de Alencar Rocha et al., 2017). The greater induction of inflammation during a period of extensive neuronal migration is particularly concerning, especially in light of recent theories that ASD may have a neuroinflammatory etiology.

In contrast to late-gestation UA ligation experiments, IUGR due to chronic maternal malnutrition throughout pregnancy results in an "area under the curve" characterized by a low dose insult over a long duration. While the magnitude of the Dose $\times$ Duration area under the curve may be similar to UA ligation, the shape is decidedly different, with many more periods of critical regional development at risk. The effects of IUGR due to maternal malnutrition are more global than UA ligation.
Macronutrient IUGR models restrict protein or protein + energy intake of the mother beginning early in the first trimester. The nutrient restriction is present throughout pregnancy and is frequently severe with the dams receiving as little as $50 \%$ of their normal intake. The effect of protein restriction at various stages of pregnancy has been described in rodent models since 1975 (Koshy, Sara, King, \& Lazarus, 1975).

The global findings in these preclinical models corroborate the findings from autopsy studies in human infants including a reduction in brain size due primarily to loss of neuronal number (Rosso et al., 1970; Winick, 1971). The models suggest that maternal malnutrition affects the rate of brain development by causing premature cessation of neurogenesis and an earlier switch from proliferation to cell differentiation (Koshy et al., 1975). IUGR induced by a low-protein diet given to the rat dam starting on Day 1 of pregnancy reduces overall myelination and connectivity in the offspring. Significant deregulation of genes controlling neuroinflammation occurs, allowing for a more pro-inflammatory state in the developing brain (Rideau Batista Novais et al., 2016). The authors suggest that neuroinflammation due to IUGR may provide a biological explanation for poor cognitive outcome in IUGR humans (Rideau Batista Novais et al., 2016).

As with UA ligation, regional brain effects are also seen with protein and protein-energy restriction. The hypothalamus is reprogrammed with respect to satiety and hunger cues, which may relate to appetite regulation issues and metabolic syndrome seen in adulthood following IUGR (Pedroso et al., 2017). IUGR also lowers cerebral weight, resulting in fewer neurons through increased apoptosis accompanied by reduction in PKA-CREB signaling pathway activity (Liu, Liu, \& Chen, 2011; Liu, Liu, Wang, Chen, \& Yang, 2013). Synaptic counts are reduced, and glial cell proliferation is suppressed in the cortex (Liu et al., 2011). IUGR increases oxidative stress and results in lipid peroxidation in the cerebellum and the cerebral cortex (Tatli et al., 2007).

Behaviorally, the long-term effects are particularly magnified if malnutrition continues postnatally after IUGR. Rat pups born to dams on a low-protein diet and maintained on that diet to adulthood have poor spatial learning and memory. Male offspring have more hyperactivity than females (Naik, Patro, \& Patro, 2015). IUGR followed by postnatal growth restriction increases anxiety in males and females in young adulthood, but without social or cognitive impairment. Nevertheless, both males and females exhibit increased biochemical evidence of Alzheimer disease at 15-17 months with more astrogliosis and a tenfold increase in amyloid-beta42 protein expression (Tomi, Zhao, Thamotharan, Shin, \& Devaskar, 2013).

Studies of both IUGR human cohorts and animal models have provided evidence for epigenetic programming of the epigenome (Heijmans et al., 2009; Joss-Moore, Albertine, \& Lane, 2011; Simmons, 2007; Tobi et al., 2009). DNA methylation was examined at the regulatory regions of 15 genes associated with cardiovascular and metabolic disease in adults who were exposed to famine (members of the Dutch famine cohort) during gestation. Gestational famine signifi- 
cantly altered the DNA methylation at 6 of these 15 gene regulatory loci, indicating that gene expression might be altered in these individuals, even in adulthood, long after the period of gestational famine (Heijmans et al., 2009; Tobi et al., 2009). Both modifications of DNA and histones have been demonstrated in IUGR animal models, particularly in genes that have important roles in brain development and brain health across the life span (Joss-Moore et al., 2011; Simmons, 2007).

\section{Concluding Remarks}

Clinically, psychopathologies are thought of as discrete entities (as found in the DSM-5 or ICD-10) with little overlap, and their diagnosis points toward specific treatment protocols (Caspi et al., 2014). Practically, there can be difficulty even with experienced clinicians in distinguishing between presentations of different psychiatric illnesses, as diagnosis often entirely relies on presenting signs and symptoms, without regard to the underlying neurobiology (Cuthbert \& Insel, 2013). This is especially true in children, where comorbidity of different psychopathologies is more common than in adults (Angold, Costello, \& Erkanli, 1999). This is especially notable in that genes identified as risk factors (via genome-wide association studies in this reference) in multiple psychopathologies have remarkable overlap (Cross-Disorder Group of the Psychiatric Genomics Consortium, 2013), and meta analyses of imaging studies have found neural substrates common for both individual psychiatric entities (an affective subdivision of the corticostriatal-pallidal-thalamic circuit in depression; Hamilton et al., 2012) and common to multiple psychiatric diagnoses (i.e., transdiagnostically across different psychopathologies; gray matter loss in the dorsal anterior cingulate, right insula, and left insula; Goodkind et al., 2015). These imaging studies further point toward neural substrates supporting specific behaviors (increased salience of negative information in major depressive disorder and a transdiagnostic association with poorer executive functioning). A fundamental question with respect to psychopathology resulting from events of commission or omission in the intrauterine environment is whether these are purely environmental influences or if they represent an interaction between gene and environment, which could be mistaken for either genetic traits or environmental insults. For example, evidence from twin studies demonstrates a large correlation between internalizing and externalizing factors, with a strong genetic influence (Cosgrove et al., 2011; Lahey, van Hulle, Singh, Waldman, \& Rathouz, 2011). Internalizing behaviors are considered "overcontrolled" behaviors characterized by anxiety and depression, whereas externalizing behaviors are considered "undercontrolled" and characterized by aggression and hyperactivity (Achenbach \& Edelbrock, 1984). In this same study, psychiatric disorder-specific causes were mostly attributed to nonshared environmental influences. These results are consistent with a "generalist gene, specialist environments model" of psychopathology (Eley, 1997). Internalizing and externalizing behaviors, while distinguishable, may reflect a common neurobiological substrate that results in negative emotionality, a transdiagnostic construct that may explain genetic or Gene $\times$ Environment influences on behavior (Rhee, Lahey, \& Waldman, 2015). Many of the conditions we reviewed here result in changes in internalizing and externalizing behaviors, or in the case of prenatal alcohol exposure, ID, and IUGR, executive functioning. Executive functions include updating/working memory, inhibition, and shifting/ selective attention and may encompass internalizing and externalizing behaviors (Alvarez \& Emory, 2006; Miyake \& Friedman, 2012). Executive functioning impairments are associated with most forms of psychopathology and may be a common underlying factor accounting for life span functional impairment, family history of mental illness, prospective psychopathology, worse developmental histories, and more compromised early life brain function (Caspi et al., 2014; McTeague, Goodkind, \& Etkin, 2016; Snyder, Miyake, \& Hankin, 2015). A recent study showed that in depression, antidepressant treatment did not result in improvements in executive functioning, suggesting that common treatments are ineffective in affecting this domain (Shilyansky et al., 2016). The conditions we have reviewed here may provide insight into neurobiological substrates that underlie transdiagnostic entities such as negative emotionality or executive functioning, which in turn, may point toward discovery of "generalist" genes (affected by epigenetic mechanisms) and brain structures for targeted therapeutics.

In this article, we have presented information that provides biological plausibility to support the hypothesis that common fetal events affect brain development and function across the life span through a variety of mechanisms. While the literature has moved over the decades from describing the global effects of these events to documenting more regionally specific effects, it still tends to focus on "one event-one brain region" types of analyses. This approach stems from classic neuroscience research thinking in relatively static adult brains where accidents of nature in humans are used to decipher what a given brain area "does" (e.g., a stroke in the motor cortex leads to hemiplegia). The same rules do not appear to apply to the developing fetal and neonatal brain because of the incompleteness of its circuitry at the time of the environmental event and the enormous plasticity that the young brain exhibits. Thus, development itself becomes a mediating factor in the ultimate behavioral outcome.

A greater understanding of how affected (and nonaffected) regions interact at the circuit level is critical to truly understand the effect of prenatal events on complex behaviors. Given the commonality of circuits affected (by global metabolic deficits), we no longer expect to find a "signature" effect on the developing brain based on etiology, but rather based on timing, caused by unbalanced effects on circuit inputs. Thus, different events that have a common timing (e.g., last trimester) might result in unifinality, whereas a single type of environmental disruptor can lead to multiple outcomes (multifinality) based on the timing of that single disruptor (e.g., last trimester vs. toddlerhood for iron). 


\section{References}

Abel, K. M., Wicks, S., Susser, E. S., Dalman, C., Pedersen, M. G., Mortensen, P. B., \& Webb, R. T. (2010). Birth weight, schizophrenia, and adult mental disorder: Is risk confined to the smallest babies? Archives of General Psychiatry, 67, 923-930. doi:10.1001/archgenpsychiatry.2010. 100

Achenbach, T. M., \& Edelbrock, C. S. (1984). Psychopathology of childhood. Annual Review of Psychology, 35, 227-256. doi:10.1146/annurev.ps.35.020184.001303

Adamo, A. M., \& Oteiza, P. I. (2010). Zinc deficiency and neurodevelopment: The case of neurons. BioFactors, 36, 117-124. doi:10.1002/biof.91

Algarin, C., Karunakaran, K. D., Reyes, S., Morales, C., Lozoff, B., Peirano, P., \& Biswal, B. (2017). Differences on brain connectivity in adulthood are present in subjects with iron deficiency anemia in infancy. Frontiers in Aging Neuroscience, 9, 54. doi:10.3389/fnagi.2017.00054

Algarin, C., Nelson, C. A., Peirano, P., Westerlund, A., Reyes, S., \& Lozoff, B. (2013). Iron-deficiency anemia in infancy and poorer cognitive inhibitory control at age 10 years. Developmental Medicine and Child Neurology, 55, 453-458. doi:10.1111/dmcn.12118

Allen-Institute. (2010). Allen Human Brain Atlas. Retrieved from human.brain-map.org

Alvarez, J. A., \& Emory, E. (2006). Executive function and the frontal lobes: A meta-analytic review. Neuropsychology Review, 16, 17-42. doi:10.1007/s11065-006-9002-x

Alves de Alencar Rocha, A. K., Allison, B. J., Yawno, T., Polglase, G. R., Sutherland, A. E., Malhotra, A., . . . Miller, S. L. (2017). Early- versus late-onset fetal growth restriction differentially affects the development of the fetal sheep brain. Developmental Neuroscience, 39, 141-155. doi:10.1159/000456542

Amin, S. B., Orlando, M., Eddins, A., MacDonald, M., Monczynski, C., \& Wang, H. (2010). In utero iron status and auditory neural maturation in premature infants as evaluated by auditory brainstem response. Journal of Pediatrics, 156, 377-381. doi:10.1016/j.jpeds.2009.09.049

Anderson, O. S., Nahar, M. S., Faulk, C., Jones, T. R., Liao, C., Kannan, K., ... Dolinoy, D. C. (2012). Epigenetic responses following maternal dietary exposure to physiologically relevant levels of bisphenol A. Environmental and Molecular Mutagenesis, 53, 334-342. doi:10.1002/em.21692

Angold, A., Costello, E. J., \& Erkanli, A. (1999). Comorbidity. Journal of Child Psychology and Psychiatry, and Allied Disciplines, 40, 57-87.

Arthurs, O. J., Rega, A., Guimiot, F., Belarbi, N., Rosenblatt, J., Biran, V., . . . Alison, M. (2017). Diffusion-weighted magnetic resonance imaging of the fetal brain in intrauterine growth restriction. Ultrasound in Obstetrics and Gynecology, 50, 79-87. doi:10.1002/uog.17318

Autti-Ramo, I., Autti, T., Korkman, M., Kettunen, S., Salonen, O., \& Valanne, L. (2002). MRI findings in children with school problems who had been exposed prenatally to alcohol. Developmental Medicine and Child Neurology, 44, 98-106.

Ba, A., Seri, B. V., Aka, K. J., Glin, L., \& Tako, A. (1999). Comparative effects of developmental thiamine deficiencies and ethanol exposure on the morphometry of the CA3 pyramidal cells. Neurotoxicology and Teratology, 21, 579-586.

Bale, T. L., Baram, T. Z., Brown, A. S., Goldstein, J. M., Insel, T. R., McCarthy, M. M., . . . Nestler, E. J. (2010). Early life programming and neurodevelopmental disorders. Biological Psychiatry, 68, 314-319. doi:10.1016/j.biopsych.2010.05.028

Barker, D. J. (1997). Fetal nutrition and cardiovascular disease in later life. British Medical Bulletin, 53, 96-108.

Barrett, A., Santangelo, S., Tan, K., Catchpole, S., Roberts, K., SpencerDene, B., . . . Taylor-Papadimitriou, J. (2007). Breast cancer associated transcriptional repressor PLU-1/JARID1B interacts directly with histone deacetylases. International Journal of Cancer, 121, 265-275. doi:10.1002/ijc.22673

Barua, S., Kuizon, S., Chadman, K. K., Flory, M. J., Brown, W. T., \& Junaid, M. A. (2014). Single-base resolution of mouse offspring brain methylome reveals epigenome modifications caused by gestational folic acid. Epigenetics \& Chromatin, 7, 3. doi:10.1186/1756-8935-7-3

Basavarajappa, B. S., \& Subbanna, S. (2016). Epigenetic mechanisms in developmental alcohol-induced neurobehavioral deficits. Brain Sciences, 6. doi:10.3390/brainsci6020012

Basilious, A., Yager, J., \& Fehlings, M. G. (2015). Neurological outcomes of animal models of uterine artery ligation and relevance to human intrauterine growth restriction: A systematic review. Developmental Medicine and Child Neurology, 57, 420-430. doi:10.1111/dmcn.12599
Bastian, T. W., von Hohenberg, W. C., Mickelson, D. J., Lanier, L. M., \& Georgieff, M. K. (2016). Iron deficiency impairs developing hippocampal neuron gene expression, energy metabolism, and dendrite complexity. Developmental Neuroscience, 38, 264-276. doi:10.1159/000448514

Batalle, D., Eixarch, E., Figueras, F., Munoz-Moreno, E., Bargallo, N., Illa M., . . . Gratacos, E. (2012). Altered small-world topology of structural brain networks in infants with intrauterine growth restriction and its association with later neurodevelopmental outcome. NeuroImage, 60, 1352 1366. doi:10.1016/j.neuroimage.2012.01.059

Beard, J., Erikson, K. M., \& Jones, B. C. (2003). Neonatal iron deficiency results in irreversible changes in dopamine function in rats. Journal of Nutrition, 133, 1174-1179.

Beard, J. L. (2001). Iron biology in immune function, muscle metabolism and neuronal functioning. Journal of Nutrition, 131, 568S-579S; discussion $580 \mathrm{~S}$.

Beard, J. L., Wiesinger, J. A., \& Connor, J. R. (2003). Pre- and postweaning iron deficiency alters myelination in Sprague-Dawley rats. Developmental Neuroscience, 25, 308-315. doi:10.1159/000073507

Belujon, P., \& Grace, A. A. (2008). Critical role of the prefrontal cortex in the regulation of hippocampus-accumbens information flow. Journal of Neuroscience, 28, 9797-9805. doi:10.1523/jneurosci.2200-08.2008

Berman, R. F., \& Hannigan, J. H. (2000). Effects of prenatal alcohol exposure on the hippocampus: Spatial behavior, electrophysiology, and neuroanatomy. Hippocampus, 10, 94-110. doi:10.1002/(sici)1098-1063(2000) 10:1<94::aid-hipo11>3.0.co;2-t

Beyer, S., Kristensen, M. M., Jensen, K. S., Johansen, J. V., \& Staller, P. (2008). The histone demethylases JMJD1A and JMJD2B are transcriptional targets of hypoxia-inducible factor HIF. Journal of Biological Chemistry, 283, 36542-36552. doi:10.1074/jbc.M804578200

Blegen, M. B., Kennedy, B. C., Thibert, K. A., Gewirtz, J. C., Tran, P. V., \& Georgieff, M. K. (2013). Multigenerational effects of fetal-neonatal iron deficiency on hippocampal BDNF signaling. Physiological Reports, 1, e00096. doi: $10.1002 /$ phy2.96

Bookstein, F. L., Connor, P. D., Covell, K. D., Barr, H. M., Gleason, C. A., Sze, R. W., . . . Streissguth, A. P. (2005). Preliminary evidence that prenatal alcohol damage may be visible in averaged ultrasound images of the neonatal human corpus callosum. Alcohol, 36, 151-160. doi:10.1016/ j.alcohol.2005.07.007

Bookstein, F. L., Connor, P. D., Huggins, J. E., Barr, H. M., Pimentel, K. D., \& Streissguth, A. P. (2007). Many infants prenatally exposed to high levels of alcohol show one particular anomaly of the corpus callosum. $A l$ coholism, Clinical and Experimental Research, 31, 868-879. doi:10.1111/j.1530-0277.2007.00367.x

Bookstein, F. L., Sampson, P. D., Streissguth, A. P., \& Connor, P. D. (2001) Geometric morphometrics of corpus callosum and subcortical structures in the fetal-alcohol-affected brain. Teratology, 64, 4-32. doi:10.1002/tera.1044

Braun, J. M., \& Hauser, R. (2011). Bisphenol A and children's health. Current Opinion in Pediatrics, 23, 233-239. doi:10.1097/ MOP.0b013e3283445675

Braun, J. M., Yolton, K., Dietrich, K. N., Hornung, R., Ye, X., Calafat, A. M., \& Lanphear, B. P. (2009). Prenatal bisphenol A exposure and early childhood behavior. Environmental Health Perspectives, 117, 1945-1952. doi:10.1289/ehp.0900979

Brunette, K. E., Tran, P. V., Wobken, J. D., Carlson, E. S., \& Georgieff, M. K. (2010). Gestational and neonatal iron deficiency alters apical dendrite structure of CA1 pyramidal neurons in adult rat hippocampus. Developmental Neuroscience, 32, 238-248. doi:10.1159/000314341

Businelli, C., de Wit, C., Visser, G. H., \& Pistorius, L. R. (2014). Ultrasound evaluation of cortical brain development in fetuses with intrauterine growth restriction. Journal of Maternal-Fetal \& Neonatal Medicine, 10, 1-6. doi:10.3109/14767058.2014.953474

Caetano, A. C., Zamarian, A. C., Araujo Junior, E., Cavalcante, R. O., Simioni, C., Silva, C. P., . . Nardozza, L. M. (2015). Assessment of intracranial structure volumes in fetuses with growth restriction by 3-dimensional sonography using the extended imaging virtual organ computeraided analysis method. Journal of Ultrasound in Medicine, 34, 13971405. doi:10.7863/ultra.34.8.1397

Callahan, L. S., Thibert, K. A., Wobken, J. D., \& Georgieff, M. K. (2013). Early-life iron deficiency anemia alters the development and long-term expression of parvalbumin and perineuronal nets in the rat hippocampus. Developmental Neuroscience, 35, 427-436. doi:10.1159/000354178

Cannon, M., Jones, P. B., \& Murray, R. M. (2002). Obstetric complications and schizophrenia: Historical and meta-analytic review. American Journal of Psychiatry, 159, 1080-1092. doi:10.1176/appi.ajp.159.7.1080 
Carlson, E. S., Fretham, S. J., Unger, E., O’Connor, M., Petryk, A., Schallert, T., ... Georgieff, M. K. (2010). Hippocampus specific iron deficiency alters competition and cooperation between developing memory systems. Journal of Neurodevelopmental Disorders, 2, 133-143. doi:10.1007/ s11689-010-9049-0

Carlson, E. S., Stead, J. D., Neal, C. R., Petryk, A., \& Georgieff, M. K. (2007). Perinatal iron deficiency results in altered developmental expression of genes mediating energy metabolism and neuronal morphogenesis in hippocampus. Hippocampus, 17, 679-691. doi:10.1002/hipo.20307

Carlson, E. S., Tkac, I., Magid, R., O'Connor, M. B., Andrews, N. C., Schallert, T., . . . Petryk, A. (2009). Iron is essential for neuron development and memory function in mouse hippocampus. Journal of Nutrition, 139, 672-679. doi:10.3945/jn.108.096354

Carter, R. C., Jacobson, J. L., Burden, M. J., Armony-Sivan, R., Dodge, N. C., Angelilli, M. L., . . . Jacobson, S. W. (2010). Iron deficiency anemia and cognitive function in infancy. Pediatrics, 126, e427-e434. doi:10.1542/peds.2009-2097

Casas, M., Forns, J., Martinez, D., Avella-Garcia, C., Valvi, D., BallesterosGomez, A., . . V Vrijheid, M. (2015). Exposure to bisphenol A during pregnancy and child neuropsychological development in the INMA-Sabadell cohort. Environmental Research, 142, 671-679. doi:10.1016/j.envres.2015.07.024

Caspi, A., Houts, R. M., Belsky, D. W., Goldman-Mellor, S. J., Harrington, H., Israel, S., . . Moffitt, T. E. (2014). The p factor: One general psychopathology factor in the structure of psychiatric disorders? Clinical Psychological Science, 2, 119-137. doi:10.1177/2167702613497473

Catteau, J., Gernet, J. I., Marret, S., Legros, H., Gressens, P., Leroux, P., \& Laudenbach, V. (2011). Effects of antenatal uteroplacental hypoperfusion on neonatal microvascularisation and excitotoxin sensitivity in mice. Pediatric Research, 70, 229-235. doi:10.1203/PDR.0b013e318224285f

Chang, B., Chen, Y., Zhao, Y., \& Bruick, R. K. (2007). JMJD6 is a histone arginine demethylase. Science, 318, 444-447. doi:10.1126/science.1145801

Chater-Diehl, E. J., Laufer, B. I., \& Singh, S. M. (2017). Changes to histone modifications following prenatal alcohol exposure: An emerging picture. Alcohol, 60, 41-52. doi:10.1016/j.alcohol.2017.01.005

Chicas, A., Kapoor, A., Wang, X., Aksoy, O., Evertts, A. G., Zhang, M. Q., ... Lowe, S. W. (2012). H3K4 demethylation by Jarid $1 \mathrm{a}$ and Jarid $1 \mathrm{~b}$ contributes to retinoblastoma-mediated gene silencing during cellular senescence. Proceedings of the National Academy of Sciences of the United States of America, 109, 8971-8976. doi:10.1073/pnas.1119836109

Cho, C. E., Sanchez-Hernandez, D., Reza-Lopez, S. A., Huot, P. S., Kim, Y. I., \& Anderson, G. H. (2013). High folate gestational and post-weaning diets alter hypothalamic feeding pathways by DNA methylation in Wistar rat offspring. Epigenetics, 8, 710-719. doi:10.4161/epi.24948

Chockalingam, U. M., Murphy, E., Ophoven, J. C., Weisdorf, S. A., \& Georgieff, M. K. (1987). Cord transferrin and ferritin values in newborn infants at risk for prenatal uteroplacental insufficiency and chronic hypoxia. Journal of Pediatrics, 111, 283-286.

Christian, P., Morgan, M. E., Murray-Kolb, L., LeClerq, S. C., Khatry, S. K., Schaefer, B., ... Tielsch, J. M. (2011). Preschool iron-folic acid and zinc supplementation in children exposed to iron-folic acid in utero confers no added cognitive benefit in early school-age. Journal of Nutrition, 141, 2042-2048. doi:10.3945/jn.111.146480

Christian, P., Murray-Kolb, L. E., Khatry, S. K., Katz, J., Schaefer, B. A., Cole, P. M., ... Tielsch, J. M. (2010). Prenatal micronutrient supplementation and intellectual and motor function in early school-aged children in Nepal. Journal of the American Medical Association, 304, 2716-2723. doi:10.1001/jama.2010.1861

Clardy, S. L., Wang, X., Zhao, W., Liu, W., Chase, G. A., Beard, J. L., . . Connor, J. R. (2006). Acute and chronic effects of developmental iron deficiency on mRNA expression patterns in the brain. Journal of Neural Transmission, 71(Suppl.), 173-196.

Congdon, E. L., Westerlund, A., Algarin, C. R., Peirano, P. D., Gregas, M., Lozoff, B., \& Nelson, C. A. (2012). Iron deficiency in infancy is associated with altered neural correlates of recognition memory at 10 years. Journal of Pediatrics, 160, 1027-1033. doi:10.1016/j.jpeds.2011.12.011

Connor, J. R., \& Menzies, S. L. (1996). Relationship of iron to oligodendrocytes and myelination. Glia, 17, 83-93. doi:10.1002/(SICI)10981136(199606)17:2<83::AID-GLIA1 > 3.0.CO;2-7

Cosgrove, V. E., Rhee, S. H., Gelhorn, H. L., Boeldt, D., Corley, R. C., Ehringer, M. A., . . Hewitt, J. K. (2011). Structure and etiology of co-occurring internalizing and externalizing disorders in adolescents. Journal of Abnormal Child Psychology, 39, 109-123. doi:10.1007/s10802-010-9444-8
Cross-Disorder Group of the Psychiatric Genomics Consortium. (2013). Identification of risk loci with shared effects on five major psychiatric disorders: A genome-wide analysis. Lancet, 381, 1371-1379. doi:10.1016/ s0140-6736(12)62129-1

Cuthbert, B. N., \& Insel, T. R. (2013). Toward the future of psychiatric diagnosis: The seven pillars of RDoC. BMC Medicine, 11, 126. doi:10.1186/ 1741-7015-11-126

DeBoer, T., Wewerka, S., Bauer, P. J., Georgieff, M. K., \& Nelson, C. A. (2005). Explicit memory performance in infants of diabetic mothers at 1 year of age. Developmental Medicine and Child Neurology, 47, 525-531.

Delcour, M., Olivier, P., Chambon, C., Pansiot, J., Russier, M., Liberge, M., . Coq, J. O. (2012). Neuroanatomical, sensorimotor and cognitive deficits in adult rats with white matter injury following prenatal ischemia. Brain Pathology, 22, 1-16. doi:10.1111/j.1750-3639.2011.00504.x

Delcour, M., Russier, M., Amin, M., Baud, O., Paban, V., Barbe, M. F., \& Coq, J. O. (2012). Impact of prenatal ischemia on behavior, cognitive abilities and neuroanatomy in adult rats with white matter damage. Behavioural Brain Research, 232, 233-244. doi:10.1016/j.bbr.2012.03.029

Deregnier, R. A., Nelson, C. A., Thomas, K. M., Wewerka, S., \& Georgieff, M. K. (2000). Neurophysiologic evaluation of auditory recognition memory in healthy newborn infants and infants of diabetic mothers. Journal of Pediatrics, 137, 777-784. doi:10.1067/mpd.2000.109149

Dieni, S., \& Rees, S. (2003). Dendritic morphology is altered in hippocampal neurons following prenatal compromise. Journal of Neurobiology, 55, 41-52. doi:10.1002/neu.10194

Dieni, S., \& Rees, S. (2005). BDNF and TrkB protein expression is altered in the fetal hippocampus but not cerebellum after chronic prenatal compromise. Experimental Neurology, 192, 265-273. doi:10.1016/j.expneurol.2004.06.003

Dionne, G., Boivin, M., Seguin, J. R., Perusse, D., \& Tremblay, R. E. (2008). Gestational diabetes hinders language development in offspring. Pediatrics, 122, e1073-e1079. doi:10.1542/peds.2007-3028

Dolinoy, D. C., Huang, D., \& Jirtle, R. L. (2007). Maternal nutrient supplementation counteracts bisphenol A-induced DNA hypomethylation in early development. Proceedings of the National Academy of Sciences of the United States of America, 104, 13056-13061. doi:10.1073/pnas. 0703739104

Donald, K. A., Eastman, E., Howells, F. M., Adnams, C., Riley, E. P., Woods, R. P., . . . Stein, D. J. (2015). Neuroimaging effects of prenatal alcohol exposure on the developing human brain: A magnetic resonance imaging review. Acta Neuropsychiatrica, 27, 251-269. doi:10.1017/ neu.2015.12

Donald, K. A., Roos, A., Fouche, J. P., Koen, N., Howells, F. M., Woods, R. P., . . . Stein, D. J. (2015). A study of the effects of prenatal alcohol exposure on white matter microstructural integrity at birth. Acta Neuropsychiatrica, 27, 197-205. doi:10.1017/neu.2015.35

East, P., Lozoff, B., Blanco, E., Delker, E., Delva, J., Encina, P., \& Gahagan, S. (2017). Infant iron deficiency, child affect, and maternal unresponsiveness: Testing the long-term effects of functional isolation. Developmental Psychology, 53, 2233-2244. doi:10.1037/dev0000385

Egana-Ugrinovic, G., Sanz-Cortes, M., Figueras, F., Bargallo, N., \& Gratacos, E. (2013). Differences in cortical development assessed by fetal MRI in late-onset intrauterine growth restriction. American Journal of Obstetrics and Gynecology, 209, 126.e121-e128. doi:10.1016/j.ajog. 2013.04.008

Ehrenkranz, R. A. (2000). Growth outcomes of very low-birth weight infants in the newborn intensive care unit. Clinics in Perinatology, 27, 325-345.

Eide, M. G., Moster, D., Irgens, L. M., Reichborn-Kjennerud, T., Stoltenberg, C., Skjaerven, R., . . . Abel, K. (2013). Degree of fetal growth restriction associated with schizophrenia risk in a national cohort. Psychological Medicine, 43, 2057-2066. doi:10.1017/s003329171200267x

Eixarch, E., Munoz-Moreno, E., Bargallo, N., Batalle, D., \& Gratacos, E. (2016). Motor and cortico-striatal-thalamic connectivity alterations in intrauterine growth restriction. American Journal of Obstetrics and Gynecology, 214, 725.e721-e729. doi:10.1016/j.ajog.2015.12.028

Eley, T. C. (1997). General genes: A new theme in developmental psychopathology. Current Directions in Psychological Science, 6, 90-95.

Elsworth, J. D., Jentsch, J. D., Vandevoort, C. A., Roth, R. H., Redmond, D. E., Jr., \& Leranth, C. (2013). Prenatal exposure to bisphenol A impacts midbrain dopamine neurons and hippocampal spine synapses in nonhuman primates. Neurotoxicology, 35, 113-120. doi:10.1016/j.neuro. 2013.01.001 
Erikson, K. M., Jones, B. C., \& Beard, J. L. (2000). Iron deficiency alters dopamine transporter functioning in rat striatum. Journal of Nutrition, 130, 2831-2837.

Esmaeili, B., \& Grace, A. A. (2013). Afferent drive of medial prefrontal cortex by hippocampus and amygdala is altered in MAM-treated rats: Evidence for interneuron dysfunction. Neuropsychopharmacology, 38, 1871-1880. doi:10.1038/npp.2013.64

Evans, S. F., Kobrosly, R. W., Barrett, E. S., Thurston, S. W., Calafat, A. M., Weiss, B., ... Swan, S. H. (2014). Prenatal bisphenol A exposure and maternally reported behavior in boys and girls. Neurotoxicology, 45, 91-99. doi: $10.1016 /$ j.neuro. 2014.10 .003

Famy, C., Streissguth, A. P., \& Unis, A. S. (1998). Mental illness in adults with fetal alcohol syndrome or fetal alcohol effects. American Journal of Psychiatry, 155, 552-554. doi:10.1176/ajp.155.4.552

Fan, J., Jacobson, S. W., Taylor, P. A., Molteno, C. D., Dodge, N. C., Stanton, M. E., . . Meintjes, E. M. (2016). White matter deficits mediate effects of prenatal alcohol exposure on cognitive development in childhood. Human Brain Mapping, 37, 2943-2958. doi:10.1002/ hbm. 23218

Felt, B. T., Beard, J. L., Schallert, T., Shao, J., Aldridge, J. W., Connor, J. R., .. Lozoff, B. (2006). Persistent neurochemical and behavioral abnormalities in adulthood despite early iron supplementation for perinatal iron deficiency anemia in rats. Behavioural Brain Research, 171, 261-270. doi:10.1016/j.bbr.2006.04.001

Felt, B. T., \& Lozoff, B. (1996). Brain iron and behavior of rats are not normalized by treatment of iron deficiency anemia during early development. Journal of Nutrition, 126, 693-701.

Fretham, S. J., Carlson, E. S., \& Georgieff, M. K. (2011). The role of iron in learning and memory. Advances in Nutrition, 2, 112-121. doi:10.3945/ an. 110.000190

Fretham, S. J., Carlson, E. S., Wobken, J., Tran, P. V., Petryk, A., \& Georgieff, M. K. (2012). Temporal manipulation of transferrin-receptor-1-dependent iron uptake identifies a sensitive period in mouse hippocampal neurodevelopment. Hippocampus, 22, 1691-1702. doi:10.1002/ hipo.22004

Friel, J. K., Aziz, K., Andrews, W. L., Harding, S. V., Courage, M. L., \& Adams, R. J. (2003). A double-masked, randomized control trial of iron supplementation in early infancy in healthy term breast-fed infants. Journal of Pediatrics, 143, 582-586. doi:10.1067/s0022-3476(03) 00301-9

Fryer, S. L., Schweinsburg, B. C., Bjorkquist, O. A., Frank, L. R., Mattson, S. N., Spadoni, A. D., \& Riley, E. P. (2009). Characterization of white matter microstructure in fetal alcohol spectrum disorders. Alcoholism, Clinical and Experimental Research, 33, 514-521. doi:10.1111/j.15300277.2008.00864.x

Fuglestad, A. J., Kroupina, M. G., Johnson, D. E., \& Georgieff, M. K. (2016). Micronutrient status and neurodevelopment in internationally adopted children. Acta Paediatrica, 105, e67-e76. doi:10.1111/apa.13234

Gambling, L., Kennedy, C., \& McArdle, H. J. (2011). Iron and copper in fetal development. Seminars in Cell \& Developmental Biology, 22, 637-644. doi:10.1016/j.semcdb.2011.08.011

Gangisetty, O., Bekdash, R., Maglakelidze, G., \& Sarkar, D. K. (2014). Fetal alcohol exposure alters proopiomelanocortin gene expression and hypothalamic-pituitary-adrenal axis function via increasing MeCP2 expression in the hypothalamus. PLOS ONE, 9, e113228. doi:10.1371/journal.pone. 0113228

Gely-Pernot, A., Hao, C., Becker, E., Stuparevic, I., Kervarrec, C., Chalmel, F., ... Smagulova, F. (2015). The epigenetic processes of meiosis in male mice are broadly affected by the widely used herbicide atrazine. $B M C$ Genomics, 16, 885. doi:10.1186/s12864-015-2095-y

Geng, F., Mai, X., Zhan, J., Xu, L., Zhao, Z., Georgieff, M., . . Lozoff, B. (2015). Impact of fetal-neonatal iron deficiency on recognition memory at 2 months of age. Journal of Pediatrics, 167, 1226-1232. doi:10.1016/ j.jpeds.2015.08.035

Georgieff, M. K., Brunette, K. E., \& Tran, P. V. (2015). Early life nutrition and neural plasticity. Development and Psychopathology, 27, 411-423. doi:10.1017/s0954579415000061

Georgieff, M. K., Mills, M. M., Gordon, K., \& Wobken, J. D. (1995). Reduced neonatal liver iron concentrations after uteroplacental insufficiency. Journal of Pediatrics, 127, 308-304.

Gioiosa, L., Parmigiani, S., Vom Saal, F. S., \& Palanza, P. (2013). The effects of bisphenol A on emotional behavior depend upon the timing of exposure, age and gender in mice. Hormones and Behavior, 63, 598-605. doi:10.1016/j.yhbeh.2013.02.016
Gluckman, P. D., \& Hanson, M. A. (2004). Living with the past: Evolution, development, and patterns of disease. Science, 305, 1733-1736. doi:10.1126/science. 1095292

Golub, M. S. (2010). Recent studies of iron deficiency during brain development in nonhuman primates. BioFactors, 36, 111-116. doi:10.1002/ biof. 86

Goodkind, M., Eickhoff, S. B., Oathes, D. J., Jiang, Y., Chang, A., Jones-Hagata, L. B., . . Etkin, A. (2015). Identification of a common neurobiological substrate for mental illness. JAMA Psychiatry, 72, 305-315. doi:10.1001/jamapsychiatry.2014.2206

Goodman, J. R., Warshaw, J. B., \& Dallman, P. R. (1970). Cardiac hypertrophy in rats with iron and copper deficiency: Quantitative contribution of mitochondrial enlargement. Pediatric Research, 4, 244-256.

Grissom, N. M., \& Reyes, T. M. (2013). Gestational overgrowth and undergrowth affect neurodevelopment: Similarities and differences from behavior to epigenetics. International Journal of Developmental Neuroscience, 31, 406-414. doi:10.1016/j.ijdevneu.2012.11.006

Gunnar, M. R., \& Quevedo, K. M. (2008). Early care experiences and HPA axis regulation in children: A mechanism for later trauma vulnerability. Progress in Brain Research, 167, 137-149. doi:10.1016/s00796123(07)67010-1

Hablitz, J. J. (1986). Prenatal exposure to alcohol alters short-term plasticity in hippocampus. Experimental Neurology, 93, 423-427.

Hamilton, J. P., Etkin, A., Furman, D. J., Lemus, M. G., Johnson, R. F., \& Gotlib, I. H. (2012). Functional neuroimaging of major depressive disorder: A meta-analysis and new integration of base line activation and neural response data. American Journal of Psychiatry, 169, 693-703. doi:10.1176/appi.ajp.2012.11071105

Hao, C., Gely-Pernot, A., Kervarrec, C., Boudjema, M., Becker, E., Khil, P., ... Smagulova, F. (2016). Exposure to the widely used herbicide atrazine results in deregulation of global tissue-specific RNA transcription in the third generation and is associated with a global decrease of histone trimethylation in mice. Nucleic Acids Research, 44, 9784-9802. doi:10.1093/ nar/gkw840

Hay, W. W., Jr., Brown, L. D., Rozance, P. J., Wesolowski, S. R., \& Limesand, S. W. (2016). Challenges in nourishing the intrauterine growth-restricted foetus-Lessons learned from studies in the intrauterine growthrestricted foetal sheep. Acta Paediatrica, 105, 881-889. doi:10.1111/ apa. 13413

Hebb, D. (1949). The organization of behavior. New York: Wiley.

Heijmans, B. T., Tobi, E. W., Lumey, L. H., \& Slagboom, P. E. (2009). The epigenome: Archive of the prenatal environment. Epigenetics, 4, 526531.

Helfrich, K. K., Saini, N., Kling, P. J., \& Smith, S. M. (2017). Maternal iron nutriture as a critical modulator of FASD risk in alcohol-exposed pregnancies. Biochemistry and Cell Biology. Advance online publiction. doi:10.1139/bcb-2017-0206

Hensch, T. K. (2004). Critical period regulation. Annual Review of Neuroscience, 27, 549-579. doi:10.1146/annurev.neuro.27.070203.144327

Hicks, S. D., Middleton, F. A., \& Miller, M. W. (2010). Ethanol-induced methylation of cell cycle genes in neural stem cells. Journal of Neurochemistry, 114, 1767-1780. doi:10.1111/j.1471-4159.2010.06886.x

Horner, P. J., \& Palmer, T. D. (2003). New roles for astrocytes: The nightlife of an "astrocyte." La vida loca! Trends in Neurosciences, 26, 597-603. doi:10.1016/j.tins.2003.09.010

Huebner, S. M., Blohowiak, S. E., Kling, P. J., \& Smith, S. M. (2016). Prenatal alcohol exposure alters fetal iron distribution and elevates hepatic hepcidin in a rat model of fetal alcohol spectrum disorders. Journal of Nutrition, 146, 1180-1188. doi:10.3945/jn.115.227983

Hultman, C. M., Sparen, P., \& Cnattingius, S. (2002). Perinatal risk factors for infantile autism. Epidemiology, 13, 417-423.

Ikezuki, Y., Tsutsumi, O., Takai, Y., Kamei, Y., \& Taketani, Y. (2002). Determination of bisphenol A concentrations in human biological fluids reveals significant early prenatal exposure. Human Reproduction, 17, $2839-2841$.

Insel, B. J., Schaefer, C. A., McKeague, I. W., Susser, E. S., \& Brown, A. S (2008). Maternal iron deficiency and the risk of schizophrenia in offspring. Archives of General Psychiatry, 65, 1136-1144. doi:10.1001/ archpsyc.65.10.1136

Itoh, K., Yaoi, T., \& Fushiki, S. (2012). Bisphenol A, an endocrine-disrupting chemical, and brain development. Neuropathology, 32, 447-457. doi:10.1111/j.1440-1789.2011.01287.x

Jabes, A., Thomas, K. M., Langworthy, S., Georgieff, M. K., \& Nelson, C. A. (2015). Functional and anatomic consequences of diabetic pregnancy on 
memory in ten-year-old children. Journal of Developmental and Behavioral Pediatrics, 36, 529-535. doi:10.1097/dbp.0000000000000203

Johnson, D. E., Guthrie, D., Smyke, A. T., Koga, S. F., Fox, N. A., Zeanah, C. H., \& Nelson., C. A., III. (2010). Growth and associations between auxology, caregiving environment, and cognition in socially deprived Romanian children randomized to foster vs ongoing institutional care. Archives of Pediatrics and Adolescent Medicine, 164, 507-516. doi:10.1001/archpediatrics. 2010.56

Johnson, D. E., Miller, L. C., Iverson, S., Thomas, W., Franchino, B., Dole, K., ... Hostetter, M. K. (1992). The health of children adopted from Romania. Journal of the American Medical Association, 268, 3446-3451.

Jorgenson, L. A., Sun, M., O'Connor, M., \& Georgieff, M. K. (2005). Fetal iron deficiency disrupts the maturation of synaptic function and efficacy in area CA1 of the developing rat hippocampus. Hippocampus, 15, 10941102. doi:10.1002/hipo.20128

Jorgenson, L. A., Wobken, J. D., \& Georgieff, M. K. (2003). Perinatal iron deficiency alters apical dendritic growth in hippocampal CA1 pyramidal neurons. Developmental Neuroscience, 25, 412-420. doi:10.1159/ 000075667

Joss-Moore, L. A., Albertine, K. H., \& Lane, R. H. (2011). Epigenetics and the developmental origins of lung disease. Molecular Genetics and Metabolism, 104, 61-66. doi:10.1016/j.ymgme.2011.07.018

Kaelin, W. G., Jr., \& Ratcliffe, P. J. (2008). Oxygen sensing by metazoans: The central role of the HIF hydroxylase pathway. Molecular Cell, 30, 393-402. doi:10.1016/j.molcel.2008.04.009

Kagan, K. O., \& Hamprecht, K. (2017). Cytomegalovirus infection in pregnancy. Archives of Gynecology and Obstetrics, 296, 15-26. doi:10.1007/ s00404-017-4380-2

Ke, X., McKnight, R. A., Wang, Z. M., Yu, X., Wang, L., Callaway, C. W., ... Lane, R. H. (2005). Nonresponsiveness of cerebral p53-MDM2 functional circuit in newborn rat pups rendered IUGR via uteroplacental insufficiency. American journal of physiology, 288, R1038-R1045. doi:10.1152/ajpregu.00701.2004

Ke, X., Schober, M. E., McKnight, R. A., O’Grady, S., Caprau, D., Yu, X., ... Lane, R. H. (2010). Intrauterine growth retardation affects expression and epigenetic characteristics of the rat hippocampal glucocorticoid receptor gene. Physiological Genomics, 42, 177-189. doi:10.1152/physiolgenomics.00201.2009

Ke, X., Xing, B., Yu, B., Yu, X., Majnik, A., Cohen, S., . . Joss-Moore, L. (2014). IUGR disrupts the PPARgamma-Setd8-H4K20me(1) and Wnt signaling pathways in the juvenile rat hippocampus. International Journal of Developmental Neuroscience, 38, 59-67. doi:10.1016/j.ijdevneu.2014.07.008

Kertes, D. A., Gunnar, M. R., Madsen, N. J., \& Long, J. D. (2008). Early deprivation and home basal cortisol levels: A study of internationally adopted children. Development and Psychopathology, 20, 473-491. doi:10.1017/ s0954579408000230

Kim, P., Park, J. H., Choi, C. S., Choi, I., Joo, S. H., Kim, M. K., . . Shin, C. Y. (2013). Effects of ethanol exposure during early pregnancy in hyperactive, inattentive and impulsive behaviors and MeCP2 expression in rodent offspring. Neurochemical Research, 38, 620-631. doi:10.1007/ s11064-012-0960-5

Kimura, K. A., Reynolds, J. N., \& Brien, J. F. (2000). Ethanol neurobehavioral teratogenesis and the role of the hippocampal glutamate-N-methylD-aspartate receptor-nitric oxide synthase system. Neurotoxicology and Teratology, 22, 607-616.

Kingdon, D., Cardoso, C., \& McGrath, J. J. (2016). Research Review: Executive function deficits in fetal alcohol spectrum disorders and attentiondeficit/hyperactivity disorder-A meta-analysis. Journal of Child Psychology and Psychiatry, and Allied Disciplines, 57, 116-131. doi: $10.1111 /$ jcpp. 12451

Kleiber, M. L., Mantha, K., Stringer, R. L., \& Singh, S. M. (2013). Neurodevelopmental alcohol exposure elicits long-term changes to gene expression that alter distinct molecular pathways dependent on timing of exposure. Journal of Neurodevelopmental Disorders, 5, 6. doi:10.1186/ 1866-1955-5-6

Klintsova, A. Y., Helfer, J. L., Calizo, L. H., Dong, W. K., Goodlett, C. R., \& Greenough, W. T. (2007). Persistent impairment of hippocampal neurogenesis in young adult rats following early postnatal alcohol exposure. $\mathrm{Al}$ coholism, Clinical and Experimental Research, 31, 2073-2082. doi:10.1111/j.1530-0277.2007.00528.x

Kolk, S. M., Gunput, R. A., Tran, T. S., van den Heuvel, D. M., Prasad, A. A., Hellemons, A. J., . . Pasterkamp, R. J. (2009). Semaphorin 3F is a bifunctional guidance cue for dopaminergic axons and controls their fasci- culation, channeling, rostral growth, and intracortical targeting. Journal of Neuroscience, 29, 12542-12557. doi:10.1523/jneurosci.252109.2009

Koshy, T. S., Sara, V. R., King, T. L., \& Lazarus, L. (1975). The influence of protein restriction imposed at various stages of pregnancy on fetal and placental development. Growth, 39, 497-506.

Kouzarides, T. (2007). Chromatin modifications and their function. Cell, 128, 693-705. doi:S0092-8674(07)00184-5 [pii]10.1016/j.cell.2007. 02.005

Krahl, S. E., Berman, R. F., \& Hannigan, J. H. (1999). Electrophysiology of hippocampal CA1 neurons after prenatal ethanol exposure. Alcohol, 17, $125-131$.

Krakowiak, P., Walker, C. K., Bremer, A. A., Baker, A. S., Ozonoff, S., Hansen, R. L., \& Hertz-Picciotto, I. (2012). Maternal metabolic conditions and risk for autism and other neurodevelopmental disorders. Pediatrics, 129, e1121-e1128. doi:10.1542/peds.2011-2583

Kretchmer, N., Beard, J. L., \& Carlson, S. (1996). The role of nutrition in the development of normal cognition. American Journal of Clinical Nutrition, 63, 997s-1001s.

Kuzawa, C. W. (1998). Adipose tissue in human infancy and childhood: An evolutionary perspective. American Journal of Physical Anthropology, 27, 177-209.

Lahey, B. B., van Hulle, C. A., Singh, A. L., Waldman, I. D., \& Rathouz, P. J. (2011). Higher-order genetic and environmental structure of prevalent forms of child and adolescent psychopathology. Archives of General Psychiatry, 68, 181-189. doi:10.1001/archgenpsychiatry.2010.192

Lahti, J., Raikkonen, K., Kajantie, E., Heinonen, K., Pesonen, A. K., Jarvenpaa, A. L., \& Strandberg, T. (2006). Small body size at birth and behavioural symptoms of ADHD in children aged five to six years. Journal of Child Psychology and Psychiatry, and Allied Disciplines, 47, 11671174. doi:10.1111/j.1469-7610.2006.01661.x

Lane, R. H., Ramirez, R. J., Tsirka, A. E., Kloesz, J. L., McLaughlin, M. K., Gruetzmacher, E. M., \& Devaskar, S. U. (2001). Uteroplacental insufficiency lowers the threshold towards hypoxia-induced cerebral apoptosis in growth-retarded fetal rats. Brain Research, 895, 186-193.

Lange, S., Rehm, J., Anagnostou, E., \& Popova, S. (2017). Prevalence of externalizing disorders and autism spectrum disorder among children with fetal alcohol spectrum disorder: Systematic review and meta-analysis. Biochemistry and Cell Biology. Advance online publication. doi:10.1139/bcb-2017-0014

Laufer, B. I., Mantha, K., Kleiber, M. L., Diehl, E. J., Addison, S. M., \& Singh, S. M. (2013). Long-lasting alterations to DNA methylation and ncRNAs could underlie the effects of fetal alcohol exposure in mice. Disease Models \& Mechanisms, 6, 977-992. doi:10.1242/ dmm.010975

Lebel, C., Rasmussen, C., Wyper, K., Andrew, G., \& Beaulieu, C. (2010). Brain microstructure is related to math ability in children with fetal alcohol spectrum disorder. Alcoholism, Clinical and Experimental Research, 34, 354-363. doi:10.1111/j.1530-0277.2009.01097.x

Lebel, C., Rasmussen, C., Wyper, K., Walker, L., Andrew, G., Yager, J., \& Beaulieu, C. (2008). Brain diffusion abnormalities in children with fetal alcohol spectrum disorder. Alcoholism, Clinical and Experimental Research, 32, 1732-1740. doi:10.1111/j.1530-0277.2008.00750.x

Lee, H. Y., Choi, K., Oh, H., Park, Y. K., \& Park, H. (2014). HIF-1-dependent induction of Jumonji domain-containing protein (JMJD) 3 under hypoxic conditions. Molecules and Cells, 37, 43-50. doi:10.14348/molcells. 2014.2250

Leonard, H., de Klerk, N., Bourke, J., \& Bower, C. (2006). Maternal health in pregnancy and intellectual disability in the offspring: A population-based study. Annals of Epidemiology, 16, 448-454. doi:10.1016/j.annepidem.2005.05.002

Lim, Y. H., Bae, S., Kim, B. N., Shin, C. H., Lee, Y. A., Kim, J. I., \& Hong, Y. C. (2017). Prenatal and postnatal bisphenol A exposure and social impairment in 4-year-old children. Environmental Health, 16, 79. doi:10.1186/s12940-017-0289-2

Lisman, J. E., Coyle, J. T., Green, R. W., Javitt, D. C., Benes, F. M., Heckers, S., \& Grace, A. A. (2008). Circuit-based framework for understanding neurotransmitter and risk gene interactions in schizophrenia. Trends in Neurosciences, 31, 234-242. doi:10.1016/j.tins.2008.02.005

Liu, Y., Balaraman, Y., Wang, G., Nephew, K. P., \& Zhou, F. C. (2009). Alcohol exposure alters DNA methylation profiles in mouse embryos at early neurulation. Epigenetics, 4, 500-511.

Liu, J., Liu, L., \& Chen, H. (2011). Antenatal taurine supplementation for improving brain ultrastructure in fetal rats with intrauterine growth restric- 
tion. Neuroscience, 181, 265-270. doi:10.1016/j.neuroscience.2011.02. 056

Liu, J., Liu, Y., Wang, X. F., Chen, H., \& Yang, N. (2013). Antenatal taurine supplementation improves cerebral neurogenesis in fetal rats with intrauterine growth restriction through the PKA-CREB signal pathway. Nutritional Neuroscience, 16, 282-287. doi:10.1179/1476830513y.00000000 57

Livy, D. J., Miller, E. K., Maier, S. E., \& West, J. R. (2003). Fetal alcohol exposure and temporal vulnerability: Effects of binge-like alcohol exposure on the developing rat hippocampus. Neurotoxicology and Teratology, 25, 447-458.

Liyanage, V. R., Zachariah, R. M., Davie, J. R., \& Rastegar, M. (2015). Ethanol deregulates Mecp2/MeCP2 in differentiating neural stem cells via interplay between 5-methylcytosine and 5-hydroxymethylcytosine at the Mecp2 regulatory elements. Experimental Neurology, 265, 102-117. doi:10.1016/j.expneurol.2015.01.006

Lodygensky, G. A., Seghier, M. L., Warfield, S. K., Tolsa, C. B., Sizonenko, S., Lazeyras, F., \& Huppi, P. S. (2008). Intrauterine growth restriction affects the preterm infant's hippocampus. Pediatric Research, 63, 438443. doi:10.1203/PDR.0b013e318165c005

Lozoff, B., Beard, J., Connor, J., Barbara, F., Georgieff, M., \& Schallert, T. (2006). Long-lasting neural and behavioral effects of iron deficiency in infancy. Nutrition Reviews, 64(5, Pt. 2), S34-S43; discussion S72-S91.

Lozoff, B., Clark, K. M., Jing, Y., Armony-Sivan, R., Angelilli, M. L., \& Jacobson, S. W. (2008). Dose-response relationships between iron deficiency with or without anemia and infant social-emotional behavior. Journal of Pediatrics, 152, 696-702. doi:10.1016/j.jpeds.2007.09.048

Lozoff, B., De Andraca, I., Castillo, M., Smith, J. B., Walter, T., \& Pino, P. (2003). Behavioral and developmental effects of preventing iron-deficiency anemia in healthy full-term infants. Pediatrics, 112, 846-854.

Lozoff, B., \& Georgieff, M. K. (2006). Iron deficiency and brain development. Seminars in Pediatric Neurology, 13, 158-165. doi:S10719091(06)00103-3[pii]10.1016/j.spen.2006.08.004

Lozoff, B., Jimenez, E., Hagen, J., Mollen, E., \& Wolf, A. W. (2000). Poorer behavioral and developmental outcome more than 10 years after treatment for iron deficiency in infancy. Pediatrics, 105, E51.

Lozoff, B., Smith, J. B., Kaciroti, N., Clark, K. M., Guevara, S., \& Jimenez, E. (2013). Functional significance of early-life iron deficiency: Outcomes at 25 years. Journal of Pediatrics, 163, 1260-1266. doi:10.1016/ j.jpeds.2013.05.015

Lubin, F. D., Roth, T. L., \& Sweatt, J. D. (2008). Epigenetic regulation of BDNF gene transcription in the consolidation of fear memory. Journal of Neuroscience, 28, 10576-10586. doi:10.1523/jneurosci.178608.2008

Lukowski, A. F., Koss, M., Burden, M. J., Jonides, J., Nelson, C. A., Kaciroti, N., . . Lozoff, B. (2010). Iron deficiency in infancy and neurocognitive functioning at 19 years: Evidence of long-term deficits in executive function and recognition memory. Nutritional Neuroscience, 13, 54-70. doi:10.1179/147683010×12611460763689

Macht, V. A., Kelly, S. J., \& Gass, J. T. (2017). Sex-specific effects of developmental alcohol exposure on cocaine-induced place preference in adulthood. Behavioural Brain Research, 332, 259-268. doi:10.1016/ j.bbr.2017.06.003

Maier, S. E., Miller, J. A., Blackwell, J. M., \& West, J. R. (1999). Fetal alcohol exposure and temporal vulnerability: Regional differences in cell loss as a function of the timing of binge-like alcohol exposure during brain development. Alcoholism, Clinical and Experimental Research, 23, 726734.

Malisza, K. L., Buss, J. L., Bolster, R. B., de Gervai, P. D., Woods-Frohlich, L., Summers, R., . . Longstaffe, S. (2012). Comparison of spatial working memory in children with prenatal alcohol exposure and those diagnosed with ADHD: A functional magnetic resonance imaging study. Journal of Neurodevelopmental Disorders, 4, 12. doi:10.1186/18661955-4-12

Mallard, C., Loeliger, M., Copolov, D., \& Rees, S. (2000). Reduced number of neurons in the hippocampus and the cerebellum in the postnatal guinea-pig following intrauterine growth-restriction. Neuroscience, 100, 327-333.

Mallard, E. C., Rehn, A., Rees, S., Tolcos, M., \& Copolov, D. (1999). Ventriculomegaly and reduced hippocampal volume following intrauterine growth-restriction: Implications for the aetiology of schizophrenia. Schizophrenia Research, 40, 11-21.

McBirney, M., King, S. E., Pappalardo, M., Houser, E., Unkefer, M., Nilsson, E., .. . Skinner, M. K. (2017). Atrazine induced epigenetic transge- nerational inheritance of disease, lean phenotype and sperm epimutation pathology biomarkers. PLOS ONE, 12, e0184306. doi:10.1371/journal.pone.0184306

McTeague, L. M., Goodkind, M. S., \& Etkin, A. (2016). Transdiagnostic impairment of cognitive control in mental illness. Journal of Psychiatric Research, 83, 37-46. doi:10.1016/j.jpsychires.2016.08.001

Menezes, J., Alves, N., Borges, S., Roehrs, R., de Carvalho Myskiw, J., Furini, C. R., . . Mello-Carpes, P. B. (2015). Facilitation of fear extinction by novelty depends on dopamine acting on D1-subtype dopamine receptors in hippocampus. Proceedings of the National Academy of Sciences of the United States of America, 112, E1652-E1658. doi:10.1073/ pnas. 1502295112

Miller, B. S., Kroupina, M. G., Mason, P., Iverson, S. L., Narad, C., Himes, J. H., . . Petryk, A. (2010). Determinants of catch-up growth in international adoptees from eastern Europe. International Journal of Pediatric Endocrinology, 2010, 107252. doi:10.1155/2010/107252

Miller, M. W. (1995). Generation of neurons in the rat dentate gyrus and hippocampus: Effects of prenatal and postnatal treatment with ethanol. Alcoholism, Clinical and Experimental Research, 19, 1500-1509.

Miodovnik, A., Engel, S. M., Zhu, C., Ye, X., Soorya, L. V., Silva, M. J., . . Wolff, M. S. (2011). Endocrine disruptors and childhood social impairment. Neurotoxicology, 32, 261-267. doi:10.1016/j.neuro.2010.12. 009

Miyake, A., \& Friedman, N. P. (2012). The nature and organization of individual differences in executive functions: Four general conclusions. Current Directions in Psychological Science, 21, 8-14. doi:10.1177/ 0963721411429458

Moffatt, M. E., Longstaffe, S., Besant, J., \& Dureski, C. (1994). Prevention of iron deficiency and psychomotor decline in high-risk infants through use of iron-fortified infant formula: A randomized clinical trial. Journal of Pediatrics, 125, 527-534.

Monk, C., Georgieff, M. K., Xu, D., Hao, X., Bansal, R., Gustafsson, H., . . Peterson, B. S. (2016). Maternal prenatal iron status and tissue organization in the neonatal brain. Pediatric Research, 79, 482-488. doi:10.1038/ pr.2015.248

Monroe, S. M., \& Simons, A. D. (1991). Diathesis-stress theories in the context of life stress research: Implications for the depressive disorders. Psychological Bulletin, 110, 406-425.

Morsing, E., Asard, M., Ley, D., Stjernqvist, K., \& Marsal, K. (2011). Cognitive function after intrauterine growth restriction and very preterm birth Pediatrics, 127, e874-e882. doi:10.1542/peds.2010-1821

Mudie, S., Bandarra, D., Batie, M., Biddlestone, J., Moniz, S., Ortmann, B., ... Rocha, S. (2014). PITX1, a specificity determinant in the HIF-1alphamediated transcriptional response to hypoxia. Cell Cycle, 13, 3878-3891. doi:10.4161/15384101.2014.972889

Murray-Kolb, L. E., \& Beard, J. L. (2007). Iron treatment normalizes cognitive functioning in young women. American Journal of Clinical Nutrition, 85, 778-787.

Naik, A. A., Patro, I. K., \& Patro, N. (2015). Slow physical growth, delayed reflex ontogeny, and permanent behavioral as well as cognitive impairments in rats following intra-generational protein malnutrition. Frontiers in Neuroscience, 9, 446. doi:10.3389/fnins.2015.00446

Nandal, A., Ruiz, J. C., Subramanian, P., Ghimire-Rijal, S., Sinnamon, R. A., Stemmler, T. L., . . Philpott, C. C. (2011). Activation of the HIF prolyl hydroxylase by the iron chaperones PCBP1 and PCBP2. Cell Metabolism, 14, 647-657. doi:10.1016/j.cmet.2011.08.015

National Institute on Alcohol Abuse and Alcoholism. (1990). 7th Special Report to the US Congress on alcohol and health: DHHS Publication ADM 90-1656. Washington, DC: National Institutes of Health.

Nelson, C. A., Wewerka, S. S., Borscheid, A. J., Deregnier, R. A., \& Georgieff, M. K. (2003). Electrophysiologic evidence of impaired crossmodal recognition memory in 8-month-old infants of diabetic mothers. Journal of Pediatrics, 142, 575-582. doi:10.1067/mpd.2003.210

Nelson, C. A., Wewerka, S., Thomas, K. M., Tribby-Walbridge, S., deRegnier R., \& Georgieff M. (2000). Neurocognitive sequelae of infants of diabetic mothers. Behavioral Neuroscience, 114, 950-956.

Nishigori, H., Mazzuca, D. M., Nygard, K. L., Han, V. K., \& Richardson, B S. (2008). BDNF and TrkB in the preterm and near-term ovine fetal brain and the effect of intermittent umbilical cord occlusion. Reproductive Sciences, 15, 895-905. doi:10.1177/1933719108324135

Niu, X., Zhang, T., Liao, L., Zhou, L., Lindner, D. J., Zhou, M., . . Yang, H. (2012). The von Hippel-Lindau tumor suppressor protein regulates gene expression and tumor growth through histone demethylase JARID1C. Oncogene, 31, 776-786. doi:10.1038/onc.2011.266 
Nosarti, C., Reichenberg, A., Murray, R. M., Cnattingius, S., Lambe, M. P., Yin, L., ... Hultman, C. M. (2012). Preterm birth and psychiatric disorders in young adult life. Archives of General Psychiatry, 69, E1-E8. doi:10.1001/archgenpsychiatry.2011.1374

Olivier, P., Baud, O., Evrard, P., Gressens, P., \& Verney, C. (2005). Prenatal ischemia and white matter damage in rats. Journal of Neuropathology and Experimental Neurology, 64, 998-1006.

Padilla, N., Falcon, C., Sanz-Cortes, M., Figueras, F., Bargallo, N., Crispi, F., ... Gratacos, E. (2011). Differential effects of intrauterine growth restriction on brain structure and development in preterm infants: A magnetic resonance imaging study. Brain Research, 1382, 98-108. doi:10.1016/ j.brainres.2011.01.032

Parnell, S. E., Holloway, H. T., O'Leary-Moore, S. K., Dehart, D. B., Paniaqua, B., Oguz, I., . . . Sulik, K. K. (2013). Magnetic resonance microscopy-based analyses of the neuroanatomical effects of gestational day 9 ethanol exposure in mice. Neurotoxicology and Teratology, 39, 7783. doi:10.1016/j.ntt.2013.07.009

Parra-Saavedra, M., Crovetto, F., Triunfo, S., Savchev, S., Peguero, A., Nadal, A., . . Figueras, F. (2014). Neurodevelopmental outcomes of nearterm small-for-gestational-age infants with and without signs of placental underperfusion. Placenta, 35, 269-274. doi:10.1016/j.placenta.2014.01. 010

Patton, S. M., Coe, C. L., Lubach, G. R., \& Connor, J. R. (2012). Quantitative proteomic analyses of cerebrospinal fluid using iTRAQ in a primate model of iron deficiency anemia. Developmental Neuroscience, 34, 354-365. doi:10.1159/000341919

Pedersen, M. T., \& Helin, K. (2010). Histone demethylases in development and disease. Trends in Cell Biology, 20, 662-671. doi:10.1016/j.tcb. 2010.08.011

Pedroso, A. P., Souza, A. P., Dornellas, A. P., Oyama, L. M., Nascimento, C. M., Santos, G. M., . . . Ribeiro, E. B. (2017). Intrauterine growth restriction programs the hypothalamus of adult male rats: Integrated analysis of proteomic and metabolomic data. Journal of Proteome Research, 16, 1515-1525. doi:10.1021/acs.jproteome.6b00923

Perera, F., Vishnevetsky, J., Herbstman, J. B., Calafat, A. M., Xiong, W., Rauh, V., \& Wang, S. (2012). Prenatal bisphenol a exposure and child behavior in an inner-city cohort. Environmental Health Perspectives, 120, 1190-1194. doi:10.1289/ehp.1104492

Perkins, A., Lehmann, C., Lawrence, R. C., \& Kelly, S. J. (2013). Alcohol exposure during development: Impact on the epigenome. International Journal of Developmental Neuroscience, 31, 391-397. doi:10.1016/j.ijdevneu.2013.03.010

Philippat, C., Nakiwala, D., Calafat, A. M., Botton, J., De Agostini, M., Heude, B., \& Slama, R. (2017). Prenatal exposure to nonpersistent endocrine disruptors and behavior in boys at 3 and 5 years. Environmental Health Perspectives, 125, 097014. doi:10.1289/ehp1314

Pinero, D., Jones, B., \& Beard, J. (2001). Variations in dietary iron alter behavior in developing rats. Journal of Nutrition, 131, 311-318.

Pisansky, M. T., Wickham, R. J., Su, J., Fretham, S., Yuan, L. L., Sun, M., , . . Georgieff, M. K. (2013). Iron deficiency with or without anemia impairs prepulse inhibition of the startle reflex. Hippocampus, 23, 952-962. doi:10.1002/hipo.22151

Poimenova, A., Markaki, E., Rahiotis, C., \& Kitraki, E. (2010). Corticosterone-regulated actions in the rat brain are affected by perinatal exposure to low dose of bisphenol A. Neuroscience, 167, 741-749. doi:10.1016/ j.neuroscience.2010.02.051

Pollard, P. J., Loenarz, C., Mole, D. R., McDonough, M. A., Gleadle, J. M., Schofield, C. J., \& Ratcliffe, P. J. (2008). Regulation of Jumonji-domaincontaining histone demethylases by hypoxia-inducible factor (HIF)-1alpha. Biochemical Journal, 416, 387-394. doi:10.1042/bj20081238

Pollitt, E., Gorman, K. S., Engle, P. L., Martorell, R., \& Rivera, J. (1993). Early supplementary feeding and cognition: Effects over two decades. Monographs of the Society for Research in Child Development, 58, 199; discussion 111-118

Pongcharoen, T., DiGirolamo, A. M., Ramakrishnan, U., Winichagoon, P., Flores, R., \& Martorell, R. (2011). Long-term effects of iron and zinc supplementation during infancy on cognitive function at $9 \mathrm{y}$ of age in northeast Thai children: A follow-up study. American Journal of Clinical Nutrition, 93, 636-643. doi:10.3945/ajen.110.002220

Pongcharoen, T., Ramakrishnan, U., DiGirolamo, A. M., Winichagoon, P., Flores, R., Singkhornard, J., \& Martorell, R. (2012). Influence of prenatal and postnatal growth on intellectual functioning in school-aged children. Archives of Pediatrics \& Adolescent Medicine, 166, 411-416. doi:10.1001/archpediatrics.2011.1413
Ponnaluri, V. K., Maciejewski, J. P., \& Mukherji, M. (2013). A mechanistic overview of TET-mediated 5-methylcytosine oxidation. Biochemical and Biophysical Research Communications, 436, 115-120. doi:10.1016/ j.bbrc.2013.05.077

Ponnusamy, R., Nissim, H. A., \& Barad, M. (2005). Systemic blockade of D2-like dopamine receptors facilitates extinction of conditioned fear in mice. Learning \& Memory, 12, 399-406. doi:10.1101/lm.96605

Popolo, M., McCarthy, D. M., \& Bhide, P. G. (2004). Influence of dopamine on precursor cell proliferation and differentiation in the embryonic mouse telencephalon. Developmental Neuroscience, 26, 229-244. doi:10.1159/ 000082140

Portales-Casamar, E., Lussier, A. A., Jones, M. J., MacIsaac, J. L., Edgar, R. D., Mah, S. M., . . . Kobor, M. S. (2016). DNA methylation signature of human fetal alcohol spectrum disorder. Epigenetics \& Chromatin, 9, 25. doi:10.1186/s13072-016-0074-4

Pylipow, M., Spector, L. G., Puumala, S. E., Boys, C., Cohen, J., \& Georgieff, M. K. (2009). Early postnatal weight gain, intellectual performance, and body mass index at 7 years of age in term infants with intrauterine growth restriction. Journal of Pediatrics, 154, 201-206. doi:10.1016/j.jpeds.2008.08.015

Raikkonen, K., Pesonen, A. K., Heinonen, K., Kajantie, E., Hovi, P., Jarvenpaa, A. L., . . . Andersson, S. (2008). Depression in young adults with very low birth weight: The Helsinki study of very low-birth-weight adults. Archives of General Psychiatry, 65, 290-296. doi:10.1001/archgenpsychiatry.2007.40

Ramadoss, S., Chen, X., \& Wang, C. Y. (2012). Histone demethylase KDM6B promotes epithelial-mesenchymal transition. Journal of Biological Chemistry, 287, 44508-44517. doi:10.1074/jbc.M112.424903

Rao, R., \& Georgieff, M. K. (2002). Perinatal aspects of iron metabolism. Acta Paediatrica, 91, 124-129.

Rao, R., Tkac, I., Schmidt, A. T., \& Georgieff, M. K. (2011). Fetal and neonatal iron deficiency causes volume loss and alters the neurochemical profile of the adult rat hippocampus. Nutritional Neuroscience, 14, 59 65. doi:10.1179/1476830511y.0000000001

Rao, R., Tkac, I., Townsend, E. L., Gruetter, R., \& Georgieff, M. K. (2003). Perinatal iron deficiency alters the neurochemical profile of the developing rat hippocampus. Journal of Nutrition, 133, 3215-3221.

Rehn, A. E., van den Buuse, M., Copolov, D., Briscoe, T., Lambert, G., \& Rees, S. (2004). An animal model of chronic placental insufficiency: Relevance to neurodevelopmental disorders including schizophrenia. Neuroscience, 129, 381-391. doi:10.1016/j.neuroscience. 2004.07.047

Reid, M. V., Murray, K. A., Marsh, E. D., Golden, J. A., Simmons, R. A., \& Grinspan, J. B. (2012). Delayed myelination in an intrauterine growth retardation model is mediated by oxidative stress upregulating bone morphogenetic protein 4. Journal of Neuropathology and Experimental Neurology, 71, 640-653. doi:10.1097/NEN.0b013e31825cfa81

Reynolds, J. D., \& Brien, J. F. (1995). Ethanol neurobehavioural teratogenesis and the role of L-glutamate in the fetal hippocampus. Canadian Journal of Physiology and Pharmacology, 73, 1209-1223.

Rhee, S. H., Lahey, B. B., \& Waldman, I. D. (2015). Comorbidity among imensions of childhood psychopathology: Converging evidence from behavior genetics. Child Development Perspectives, 9, 26-31. doi:10. 1111/cdep. 12102

Rideau Batista Novais, A., Pham, H., van de Looij, Y., Bernal, M., Mairesse, J., Zana-Taieb, E., . . . Baud, O. (2016). Transcriptomic regulations in oligodendroglial and microglial cells related to brain damage following fetal growth restriction. Glia, 64, 2306-2320. doi:10.1002/glia.23079

Riggins, T., Miller, N. C., Bauer, P. J., Georgieff, M. K., \& Nelson, C. A. (2009). Consequences of low neonatal iron status due to maternal diabetes mellitus on explicit memory performance in childhood. Developmental Neuropsychology, 34, 762-779. doi:10.1080/8756564090 3265145

Riley, E. P., Mattson, S. N., Sowell, E. R., Jernigan, T. L., Sobel, D. F., \& Jones, K. L. (1995). Abnormalities of the corpus callosum in children prenatally exposed to alcohol. Alcoholism, Clinical and Experimental Research, 19, 1198-1202.

Rizzo, T. A., Metzger, B. E., Dooley, S. L., \& Cho, N. H. (1997). Early malnutrition and child neurobehavioral development: Insights from the study of children of diabetic mothers. Child Development, 68, 26-38.

Roncagliolo, M., Garrido, M., Walter, T., Peirano, P., \& Lozoff, B. (1998). Evidence of altered central nervous system development in infants with iron deficiency anemia at $6 \mathrm{mo}$ : Delayed maturation of auditory brainstem responses. American Journal of Clinical Nutrition, 68, 683-690. 
Rosso, P., Hormazabal, J., \& Winick, M. (1970). Changes in brain weight, cholesterol, phospholipid, and DNA content in marasmic children. American Journal of Clinical Nutrition, 23, 1275-1279.

Roussotte, F. F., Sulik, K. K., Mattson, S. N., Riley, E. P., Jones, K. L., Adnams, C. M., ... Sowell, E. R. (2012). Regional brain volume reductions relate to facial dysmorphology and neurocognitive function in fetal alcohol spectrum disorders. Human Brain Mapping, 33, 920-937. doi:10. $1002 / \mathrm{hbm} .21260$

Rufer, E. S., Tran, T. D., Attridge, M. M., Andrzejewski, M. E., Flentke, G. R., \& Smith, S. M. (2012). Adequacy of maternal iron status protects against behavioral, neuroanatomical, and growth deficits in fetal alcohol spectrum disorders. PLOS ONE, 7, e47499. doi:10.1371/journal.pone.0047499

Ruff, C. A., Faulkner, S. D., Rumajogee, P., Beldick, S., Foltz, W., Corrigan, J., . . Fehlings, M. G. (2017). The extent of intrauterine growth restriction determines the severity of cerebral injury and neurobehavioural deficits in rodents. PLOS ONE, 12, e0184653. doi:10.1371/journal.pone. 0184653

Samuelsen, G. B., Pakkenberg, B., Bogdanovic, N., Gundersen, H. J., Larsen, J. F., Graem, N., \& Laursen, H. (2007). Severe cell reduction in the future brain cortex in human growth-restricted fetuses and infants. American Journal of Obstetrics and Gynecology, 197, 56. doi:10.1016/ j.ajog.2007.02.011

Sanchez-Alvarez, R., Gayen, S., Vadigepalli, R., \& Anni, H. (2013). Ethanol diverts early neuronal differentiation trajectory of embryonic stem cells by disrupting the balance of lineage specifiers. PLOS ONE, 8, e63794. doi:10.1371/journal.pone.0063794

Santhanam, P., Coles, C. D., Li, Z., Li, L., Lynch, M. E., \& Hu, X. (2011). Default mode network dysfunction in adults with prenatal alcohol exposure. Psychiatry Research, 194, 354-362. doi:10.1016/j.pscychresns.2011.05.004

Sanz-Cortes, M., Figueras, F., Bonet-Carne, E., Padilla, N., Tenorio, V., Bargallo, N., . . . Gratacos, E. (2013). Fetal brain MRI texture analysis identifies different microstructural patterns in adequate and small for gestational age fetuses at term. Fetal Diagnosis and Therapy, 33, 122-129. doi:10.1159/000346566

Schmidt, A. T., Alvarez, G. C., Grove, W. M., Rao, R., \& Georgieff, M. K. (2012). Early iron deficiency enhances stimulus-response learning of adult rats in the context of competing spatial information. Developmental Cognitive Neuroscience, 2, 174-180. doi:10.1016/j.dcn.2011.07.014

Schmidt, A. T., Waldow, K. J., Grove, W. M., Salinas, J. A., \& Georgieff, M. K. (2007). Dissociating the long-term effects of fetal/neonatal iron deficiency on three types of learning in the rat. Behavioral Neuroscience, 121, 475-482. doi:10.1037/0735-7044.121.3.475

Schmidt, R. J., Tancredi, D. J., Krakowiak, P., Hansen, R. L., \& Ozonoff, S. (2014). Maternal intake of supplemental iron and risk of autism spectrum disorder. American Journal of Epidemiology, 180, 890-900. doi:10.1093/aje/kwu208

Schober, M. E., McKnight, R. A., Yu, X., Callaway, C. W., Ke, X., \& Lane, R. H. (2009). Intrauterine growth restriction due to uteroplacental insufficiency decreased white matter and altered NMDAR subunit composition in juvenile rat hippocampi. American Journal of Physiology: Regulatory, Integrative and Comparative Physiology, 296, R681-R692. doi:10.1152/ajpregu.90396.2008

Schubert, D., Martens, G. J., \& Kolk, S. M. (2015). Molecular underpinnings of prefrontal cortex development in rodents provide insights into the etiology of neurodevelopmental disorders. Molecular Psychiatry, 20, 795809. doi:10.1038/mp.2014.147

Shafir, T., Angulo-Barroso, R., Calatroni, A., Jimenez, E., \& Lozoff, B. (2006). Effects of iron deficiency in infancy on patterns of motor development over time. Human Movement Science, 25, 821-838. doi:10.1016/ j.humov.2006.06.006

Shafir, T., Angulo-Barroso, R., Jing, Y., Angelilli, M. L., Jacobson, S. W., \& Lozoff, B. (2008). Iron deficiency and infant motor development. Early Human Development, 84, 479-485. doi:10.1016/j.earlhumdev.2007.12. 009

Sherriff, A., Emond, A., Bell, J. C., \& Golding, J. (2001). Should infants be screened for anaemia? A prospective study investigating the relation between haemoglobin at 8,12 , and 18 months and development at 18 months. Archives of Disease in Childhood, 84, 480-485.

Shilyansky, C., Williams, L. M., Gyurak, A., Harris, A., Usherwood, T., \& Etkin, A. (2016). Effect of antidepressant treatment on cognitive impairments associated with depression: A randomised longitudinal study. Lancet Psychiatry, 3, 425-435. doi:10.1016/s2215-0366(16)00012-2
Siddappa, A. M., Georgieff, M. K., Wewerka, S., Worwa, C., Nelson, C. A., \& Deregnier, R. A. (2004). Iron deficiency alters auditory recognition memory in newborn infants of diabetic mothers. Pediatric Research, 55, 1034-1041. doi:10.1203/01.pdr.0000127021.38207.62

Siddappa, A. M., Rao, R., Long, J. D., Widness, J. A., \& Georgieff, M. K (2007). The assessment of newborn iron stores at birth: A review of the literature and standards for ferritin concentrations. Neonatology, 92, 73-82. doi:10.1159/000100805

Simmons, R. (2005). Developmental origins of adult metabolic disease: Concepts and controversies. Trends in Endocrinology and Metabolism, 16, 390-394. doi:10.1016/j.tem.2005.08.004

Simmons, R. A. (2007). Developmental origins of diabetes: The role of epigenetic mechanisms. Current Opinion in Endocrinology, Diabetes, and Obesity, 14, 13-16. doi:10.1097/MED.0b013e328013da5b

Slavney, P. R., \& Grau, J. G. (1978). Fetal alcohol damage and schizophrenia. Journal of Clinical Psychiatry, 39, 782-783.

Snyder, H. R., Miyake, A., \& Hankin, B. L. (2015). Advancing understanding of executive function impairments and psychopathology: Bridging the gap between clinical and cognitive approaches. Frontiers in Psychology, 6, 328. doi:10.3389/fpsyg.2015.00328

Sowell, E. R., Mattson, S. N., Thompson, P. M., Jernigan, T. L., Riley, E. P., \& Toga, A. W. (2001). Mapping callosal morphology and cognitive correlates: Effects of heavy prenatal alcohol exposure. Neurology, 57, 235-244.

Sowell, E. R., Thompson, P. M., Mattson, S. N., Tessner, K. D., Jernigan, T. L., Riley, E. P., \& Toga, A. W. (2001). Voxel-based morphometric analyses of the brain in children and adolescents prenatally exposed to alcohol. Neuroreport, 12, 515-523.

Spottiswoode, B. S., Meintjes, E. M., Anderson, A. W., Molteno, C. D., Stanton, M. E., Dodge, N. C., . . . Jacobson, S. W. (2011). Diffusion tensor imaging of the cerebellum and eyeblink conditioning in fetal alcohol spectrum disorder. Alcoholism, Clinical and Experimental Research, 35, 2174-2183. doi:10.1111/j.1530-0277.2011.01566.x

Steinhausen, H. C., Willms, J., \& Spohr, H. L. (1993). Long-term psychopathological and cognitive outcome of children with fetal alcohol syndrome. Journal of the American Academy of Child \& Adolescent Psychiatry, 32, 990-994. doi:10.1097/00004583-199309000-00016

Streissguth, A. P., Aase, J. M., Clarren, S. K., Randels, S. P., LaDue, R. A., \& Smith, D. F. (1991). Fetal alcohol syndrome in adolescents and adults. Journal of the American Medical Association, 265, 1961-1967.

Suh, S. W., Aoyama, K., Matsumori, Y., Liu, J., \& Swanson, R. A. (2005). Pyruvate administered after severe hypoglycemia reduces neuronal death and cognitive impairment. Diabetes, 54, 1452-1458.

Susser, E., Neugebauer, R., Hoek, H. W., Brown, A. S., Lin, S., Labovitz, D. \& Gorman, J. M. (1996). Schizophrenia after prenatal famine. Further evidence. Archives of General Psychiatry, 53, 25-31.

Susser, E. S., \& Lin, S. P. (1992). Schizophrenia after prenatal exposure to the Dutch Hunger Winter of 1944-1945. Archives of General Psychiatry, 49, 983-988.

Swanson, E. C., \& Schleiss, M. R. (2013). Congenital cytomegalovirus infection: New prospects for prevention and therapy. Pediatric Clinics of North America, 60, 335-349. doi:10.1016/j.pcl.2012.12.008

Swartzwelder, H. S., Farr, K. L., Wilson, W. A., \& Savage, D. D. (1988). Prenatal exposure to ethanol decreases physiological plasticity in the hippocampus of the adult rat. Alcohol, 5, 121-124.

Swayze., V. W., II, Johnson, V. P., Hanson, J. W., Piven, J., Sato, Y., Giedd, J. N., . . Andreasen, N. C. (1997). Magnetic resonance imaging of brain anomalies in fetal alcohol syndrome. Pediatrics, 99, 232-240.

Tan, S. E., Berman, R. F., Abel, E. L., \& Zajac, C. S. (1990). Prenatal alcohol exposure alters hippocampal slice electrophysiology. Alcohol, 7, 507-511.

Tatli, M., Guzel, A., Kizil, G., Kavak, V., Yavuz, M., \& Kizil, M. (2007). Comparison of the effects of maternal protein malnutrition and intrauterine growth restriction on redox state of central nervous system in offspring rats. Brain Research, 1156, 21-30. doi:10.1016/j.brainres.2007. 04.036

Taylor, P. A., Jacobson, S. W., van der Kouwe, A., Molteno, C. D., Chen, G., Wintermark, P., . . . Meintjes, E. M. (2015). A DTI-based tractography study of effects on brain structure associated with prenatal alcohol exposure in newborns. Human Brain Mapping, 36, 170-186. doi:10.1002/ hbm. 22620

Tewar, S., Auinger, P., Braun, J. M., Lanphear, B., Yolton, K., Epstein, J. N., . . Froehlich, T. E. (2016). Association of bisphenol A exposure and attention-deficit/hyperactivity disorder in a national sample of U.S. children. Environmental Research, 150, 112-118. doi:10.1016/j.envres. 2016.05.040 
Thomas, J. D., Fleming, S. 1., \& Riley, E. P. (2001). MK-801 can exacerbate or attenuate behavioral alterations associated with neonatal alcohol exposure in the rat, depending on the timing of administration. Alcoholism, Clinical and Experimental Research, 25, 764-773.

Thompson, R. A., \& Nelson, C. A. (2001). Developmental science and the media: Early brain development. American Psychologist, 56, 5-15.

Tian, Y. H., Baek, J. H., Lee, S. Y., \& Jang, C. G. (2010). Prenatal and postnatal exposure to bisphenol a induces anxiolytic behaviors and cognitive deficits in mice. Synapse, 64, 432-439. doi:10.1002/syn.20746

Tobi, E. W., Lumey, L. H., Talens, R. P., Kremer, D., Putter, H., Stein, A. D., ... Heijmans, B. T. (2009). DNA methylation differences after exposure to prenatal famine are common and timing- and sex-specific. Human Molecular Genetics, 18, 4046-4053. doi:10.1093/hmg/ddp353

Tolsa, C. B., Zimine, S., Warfield, S. K., Freschi, M., Sancho Rossignol, A., Lazeyras, F., . . Huppi, P. S. (2004). Early alteration of structural and functional brain development in premature infants born with intrauterine growth restriction. Pediatric Research, 56, 132-138. doi:10.1203/ 01.pdr.0000128983.54614.7e

Tomi, M., Zhao, Y., Thamotharan, S., Shin, B. C., \& Devaskar, S. U. (2013). Early life nutrient restriction impairs blood-brain metabolic profile and neurobehavior predisposing to Alzheimer's disease with aging. Brain Research, 1495, 61-75. doi:10.1016/j.brainres.2012.11.050

Tran, P. V., Dakoji, S., Reise, K. H., Storey, K. K., \& Georgieff, M. K. (2013). Fetal iron deficiency alters the proteome of adult rat hippocampal synaptosomes. American Journal of Physiology: Regulatory, Integrative and Comparative Physiology, 305, R1297-R1306. doi:10.1152/ajpregu. 00292.2013

Tran, P. V., Fretham, S. J., Carlson, E. S., \& Georgieff, M. K. (2009). Longterm reduction of hippocampal brain-derived neurotrophic factor activity after fetal-neonatal iron deficiency in adult rats. Pediatric Research, 65, 493-498. doi:10.1203/PDR.0b013e31819d90a1

Tran, P. V., Kennedy, B. C., Lien, Y. C., Simmons, R. A., \& Georgieff, M. K. (2015). Fetal iron deficiency induces chromatin remodeling at the Bdnf locus in adult rat hippocampus. American Journal of Physiology: Regulatory, Integrative and Comparative Physiology, 308, R276-R282. doi:10.1152/ajpregu.00429.2014

Tran, P. V., Kennedy, B. C., Pisansky, M. T., Won, K. J., Gewirtz, J. C., Simmons, R. A., \& Georgieff, M. K. (2016). Prenatal choline supplementation diminishes early-life iron deficiency-induced reprogramming of molecular networks associated with behavioral abnormalities in the adult rat hippocampus. Journal of Nutrition, 146, 484-493. doi:10.3945/ jn.115.227561

Tyagi, E., Zhuang, Y., Agrawal, R., Ying, Z., \& Gomez-Pinilla, F. (2015). Interactive actions of Bdnf methylation and cell metabolism for building neural resilience under the influence of diet. Neurobiology of Disease, 73, 307-318. doi:10.1016/j.nbd.2014.09.014

Unger, E. L., Hurst, A. R., Georgieff, M. K., Schallert, T., Rao, R., Connor, J. R., ... Felt, B. (2012). Behavior and monoamine deficits in prenatal and perinatal iron deficiency are not corrected by early postnatal moderateiron or high-iron diets in rats. Journal of Nutrition, 142, 2040-2049. doi:10.3945/jn.112.162198

Wachs, T. D., Georgieff, M., Cusick, S., \& McEwen, B. S. (2014). Issues in the timing of integrated early interventions: Contributions from nutrition, neuroscience, and psychological research. Annals of the New York Academy of Sciences, 1308, 89-106. doi:10.1111/nyas.12314

Wachs, T. D., Pollitt, E., Cueto, S., Jacoby, E., \& Creed-Kanashiro, H. (2005). Relation of neonatal iron status to individual variability in neonatal temperament. Developmental Psychobiology, 46, 141-153. doi:10. 1002/dev.20049

Walker, S. P., Wachs, T. D., Gardner, J. M., Lozoff, B., Wasserman, G. A., Pollitt, E., \& Carter, J. A. (2007). Child development: Risk factors for adverse outcomes in developing countries. Lancet, 369, 145-157. doi:10.1016/s0140-6736(07)60076-2

White, T. P., Joseph, V., Francis, S. T., \& Liddle, P. F. (2010). Aberrant salience network (bilateral insula and anterior cingulate cortex) connectiv- ity during information processing in schizophrenia. Schizophrenia Research, 123, 105-115. doi:10.1016/j.schres.2010.07.020

Willis, W. T., Brooks, G. A., Henderson, S. A., \& Dallman, P. R. (1987). Effects of iron deficiency and training on mitochondrial enzymes in skeletal muscle. Journal of Applied Physiology, 62, 2442-2446. doi:10.1152/ jappl.1987.62.6.2442

Willoughby, K. A., Sheard, E. D., Nash, K., \& Rovet, J. (2008). Effects of prenatal alcohol exposure on hippocampal volume, verbal learning, and verbal and spatial recall in late childhood. Journal of the International Neuropsychological Society, 14, 1022-1033. doi:10.1017/s135561770 8081368

Winick, M. (1971). Effects of perinatal nutrition on CNS development and function. California Medicine, 115, 73.

Winick, M., Rosso, P., \& Waterlow, J. (1970). Cellular growth of cerebrum, cerebellum, and brain stem in normal and marasmic children. Experimental Neurology, 26, 393-400.

Wozniak, J. R., Mueller, B. A., Chang, P. N., Muetzel, R. L., Caros, L., \& Lim, K. O. (2006). Diffusion tensor imaging in children with fetal alcohol spectrum disorders. Alcoholism, Clinical and Experimental Research, 30, 1799-1806. doi:10.1111/j.1530-0277.2006.00213.x

Wozniak, J. R., Mueller, B. A., Mattson, S. N., Coles, C. D., Kable, J. A. Jones, K. L., . . . Sowell, E. R. (2017). Functional connectivity abnormalities and associated cognitive deficits in fetal alcohol Spectrum disorders (FASD). Brain Imaging and Behavior, 11, 1432-1445. doi:10.1007/s11682-016-9624-4

Wozniak, J. R., Mueller, B. A., Muetzel, R. L., Bell, C. J., Hoecker, H. L. Nelson, M. L., . . Lim, K. O. (2011). Inter-hemispheric functional connectivity disruption in children with prenatal alcohol exposure. Alcoholism, Clinical and Experimental Research, 35, 849-861. doi:10.1111/ j.1530-0277.2010.01415.x

Wozniak, J. R., Muetzel, R. L., Mueller, B. A., McGee, C. L., Freerks, M. A., Ward, E. E., . . Lim, K. O. (2009). Microstructural corpus callosum anomalies in children with prenatal alcohol exposure: An extension of previous diffusion tensor imaging findings. Alcoholism, Clinical and Experimental Research, 33, 1825-1835. doi:10.1111/j.1530-0277.2009. 01021.x

Wullschleger, S., Loewith, R., \& Hall, M. N. (2006). TOR signaling in growth and metabolism. Cell, 124, 471-484. doi:10.1016/j.cell.2006. 01.016

Xiang, A. H., Wang, X., Martinez, M. P., Walthall, J. C., Curry, E. S., Page, K., ... Getahun, D. (2015). Association of maternal diabetes with autism in offspring. Journal of the American Medical Association, 313, 14251434. doi:10.1001/jama.2015.2707

Xu, X. H., Wang, Y. M., Zhang, J., Luo, Q. Q., Ye, Y. P., \& Ruan, Q. (2010). Perinatal exposure to bisphenol-A changes N-methyl-D-aspartate receptor expression in the hippocampus of male rat offspring. Environmental Toxicology and Chemistry, 29, 176-181. doi:10.1002/etc.18

Yerushalmy-Feler, A., Marom, R., Peylan, T., Korn, A., Haham, A., Mandel, D., ... Bassan, H. (2014). Electroencephalographic characteristics in preterm infants born with intrauterine growth restriction. Journal of Pediatrics, 164, 756-761. doi:10.1016/j.jpeds.2013.12.030

Yolton, K., Xu, Y., Strauss, D., Altaye, M., Calafat, A. M., \& Khoury, J. (2011). Prenatal exposure to bisphenol A and phthalates and infant neurobehavior. Neurotoxicology and Teratology, 33, 558-566. doi:10.1016/ j.ntt.2011.08.003

Youdim, M. B., \& Green, A. R. (1978). Iron deficiency and neurotransmitter synthesis and function. Proceedings of the Nutrition Society, 37, 173179.

Zeisel, S. (2017). Choline, other methyl-donors and epigenetics. Nutrients, 9. doi:10.3390/nu9050445

Zoeller, R. T., Bansal, R., \& Parris, C. (2005). Bisphenol-A, an environmental contaminant that acts as a thyroid hormone receptor antagonist in vitro, increases serum thyroxine, and alters RC3/neurogranin expression in the developing rat brain. Endocrinology, 146, 607-612. doi:10.1210/en.2004-1018 